\title{
Synthesis of Vinca Alkaloids and Related Compounds. Part 104. A Concise Synthesis of (-)-Vincapusine
}

István Moldvai, * Tamás Gáti, Csaba Szántay Jr., and Csaba Szántay*

\section{Supporting Information}

\section{Table of contents}

Page:

S1

Contents

S2 Experimental Section. General Methods.

S3 Copy of ${ }^{1} \mathrm{H}$ NMR of derivative $6 \mathbf{a}$.

S4 Copy of ${ }^{13} \mathrm{C}$ NMR of derivative $\mathbf{6 a}$.

S5-S6 Copies of 2D NMR of derivative $6 \mathbf{a}$.

S7 Copy of ${ }^{1} \mathrm{H}$ NMR of derivative $\mathbf{6 d}$.

S8 Copy of ${ }^{13} \mathrm{C}$ NMR of derivative $\mathbf{6 d}$.

S9-S11 Copies of 2D NMR of derivative $6 \mathbf{d}$.

S12 Copy of ${ }^{1} \mathrm{H}$ NMR of derivative 7.

S13 Copy of ${ }^{13} \mathrm{C}$ NMR of derivative 7.

S14-S17 Copies of 2D NMR of derivative 7.

S18 Copy of ${ }^{1} \mathrm{H}$ NMR of derivative 8.

S19 Copy of ${ }^{13} \mathrm{C}$ NMR of derivative 8.

S20-S23 Copies of 2D NMR of derivative 8.

S24 Copy of ${ }^{1} \mathrm{H}$ NMR of derivative $4 \mathbf{a}$.

S25 Copy of ${ }^{13} \mathrm{C}$ NMR of derivative 4a.

S26-S27 Copies of 2D NMR of derivative $4 \mathbf{a}$.

S28 Copy of ${ }^{1} \mathrm{H}$ NMR of derivative $4 \mathbf{d}$.

S29 Copy of ${ }^{13} \mathrm{C}$ NMR of derivative $\mathbf{4 d}$.

S30-S32 Copies of 2D NMR of derivative $4 \mathbf{d}$.

S33 Copy of ${ }^{1} \mathrm{H}$ NMR of derivative $6 \mathbf{c}$.

S34 Copy of ${ }^{13} \mathrm{C}$ NMR of derivative $\mathbf{6 c}$.

S35-S37 Copies of 2D NMR of derivative $6 \mathbf{c}$.

S38 Copy of ${ }^{1} \mathrm{H}$ NMR of derivative $4 \mathbf{c}$.

S39 Copy of ${ }^{13} \mathrm{C}$ NMR of derivative $4 \mathbf{c}$.

S40-S42 Copies of 2D NMR of derivative $4 \mathbf{c}$. 
Experimental Section. General Methods. Melting points are uncorrected. IR spectra were obtained using a FT spectrophotometer. ${ }^{1} \mathrm{H}$ NMR and ${ }^{13} \mathrm{C}$ NMR were recorded in the solvent indicated at the experiment part, operating at $500 \mathrm{MHz}$ for ${ }^{1} \mathrm{H}$ and $125 \mathrm{MHz}$ for ${ }^{13} \mathrm{C}$ nuclei. Mass spectra were recorded using EI and/or FAB mode. High-resolution mass analyses were carried out using direct inlet spectrometers. Elemental analysis (C, H, N) were carried out by automatic microanalyzer. Chromatography was performed with $40-63 \mu \mathrm{m}$ silica gel. TLC was performed on aluminium-precoated plates of silica gel 60 with an $\mathrm{F}_{254}$ indicator and visualized under UV light or developed by iodine atmosphere and followed by immersion in a solution of $o$-tolidine of $\mathrm{EtOH}$, water and acetic acid. 


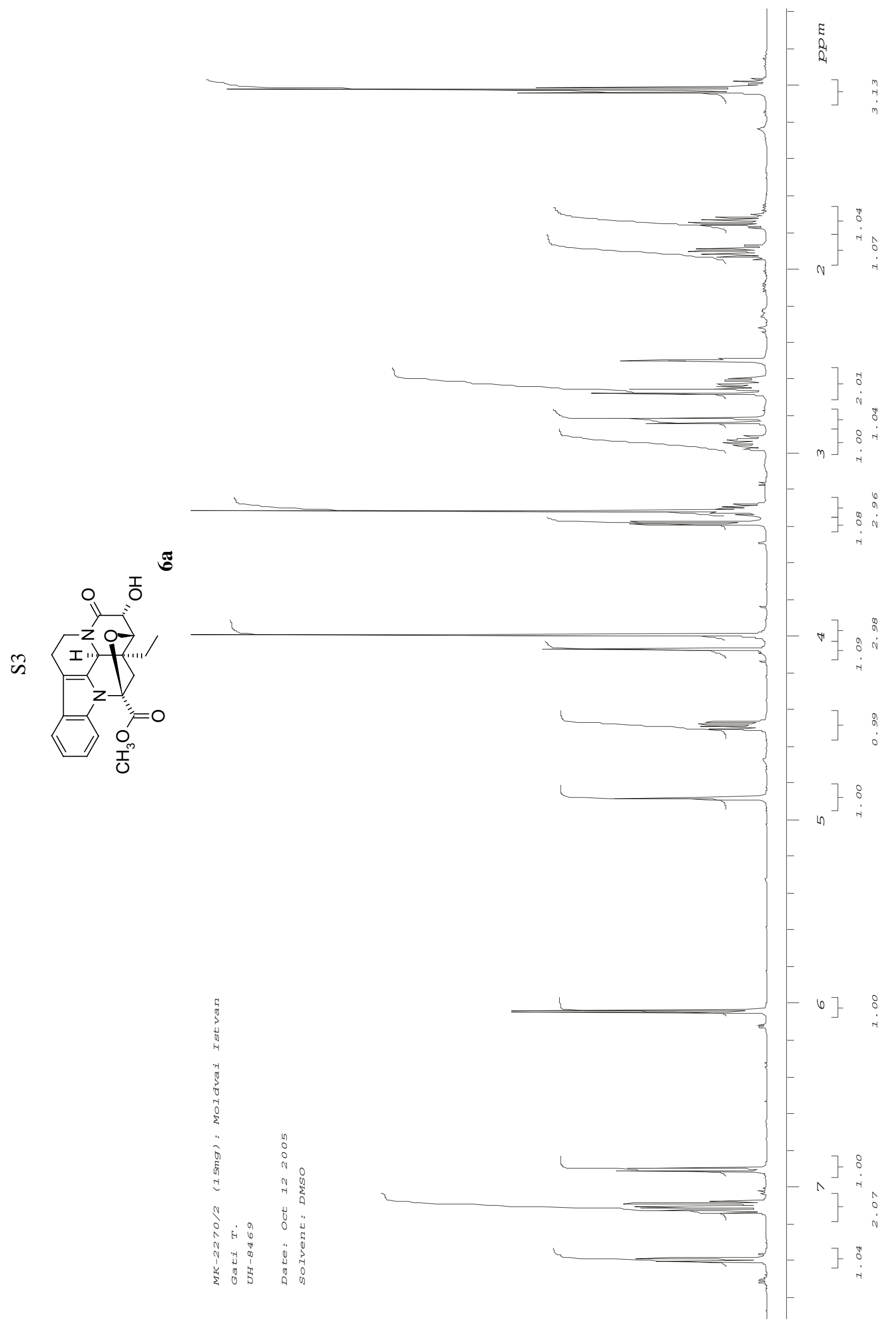




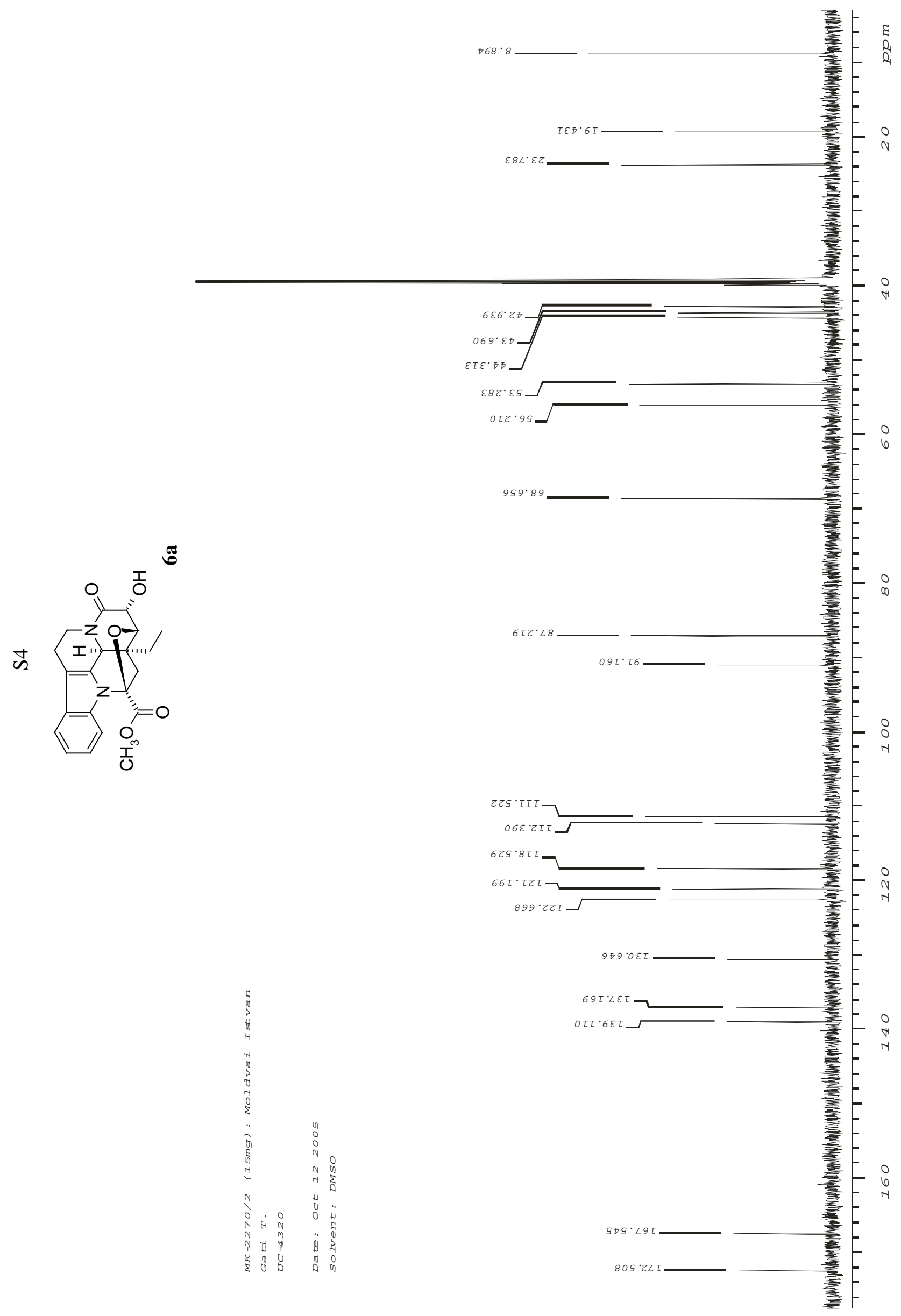




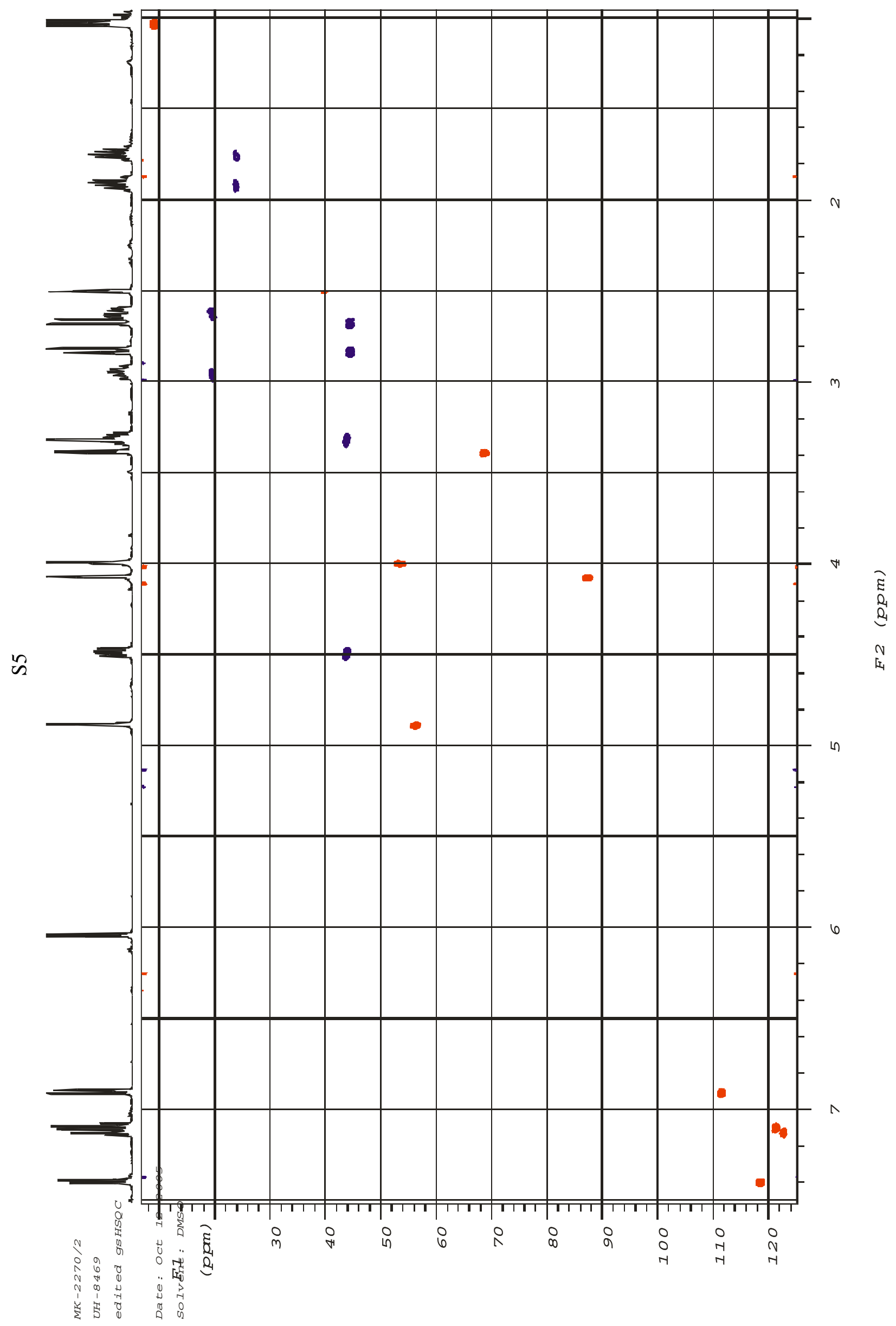




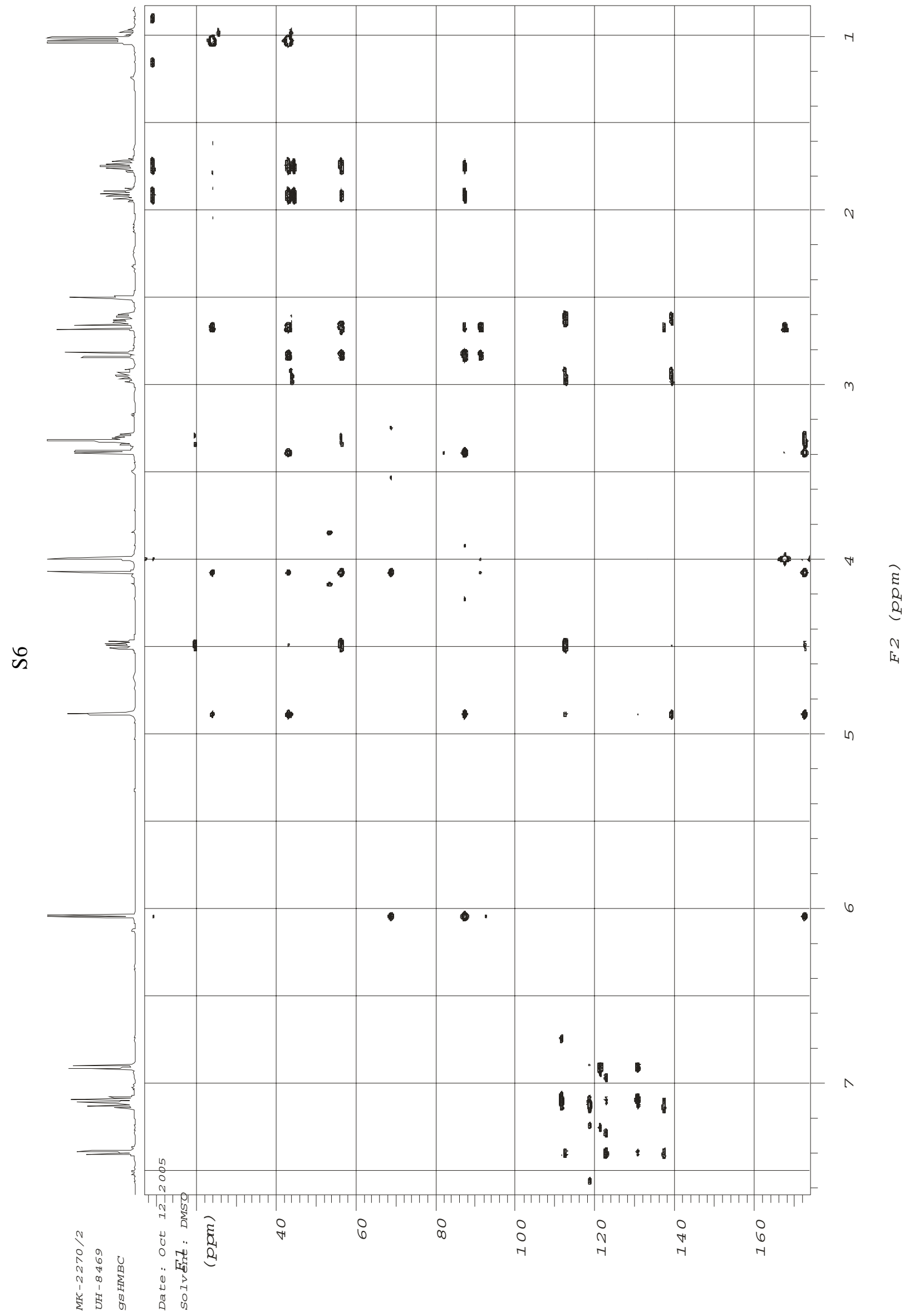



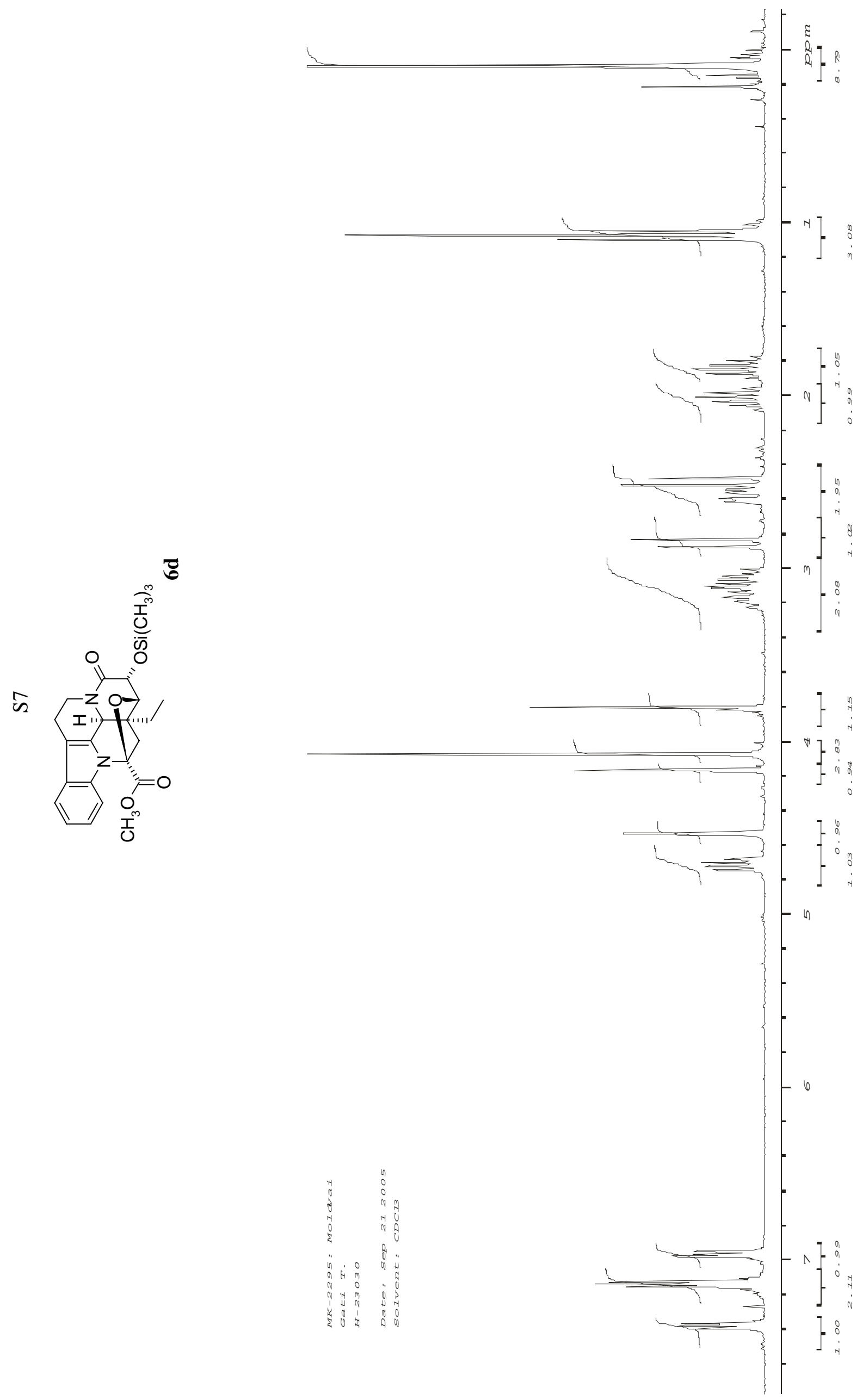

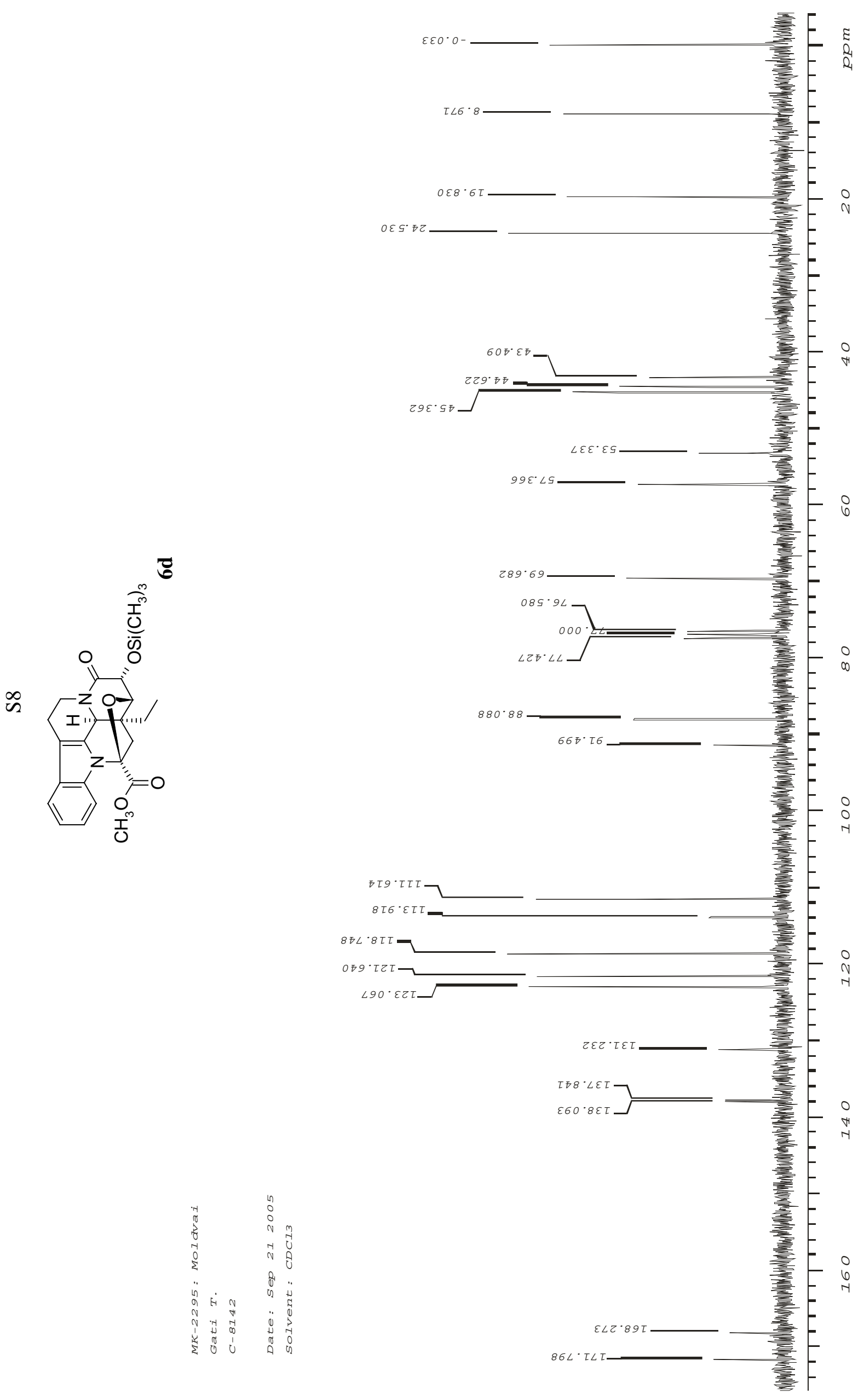


$$
\text { I" }
$$




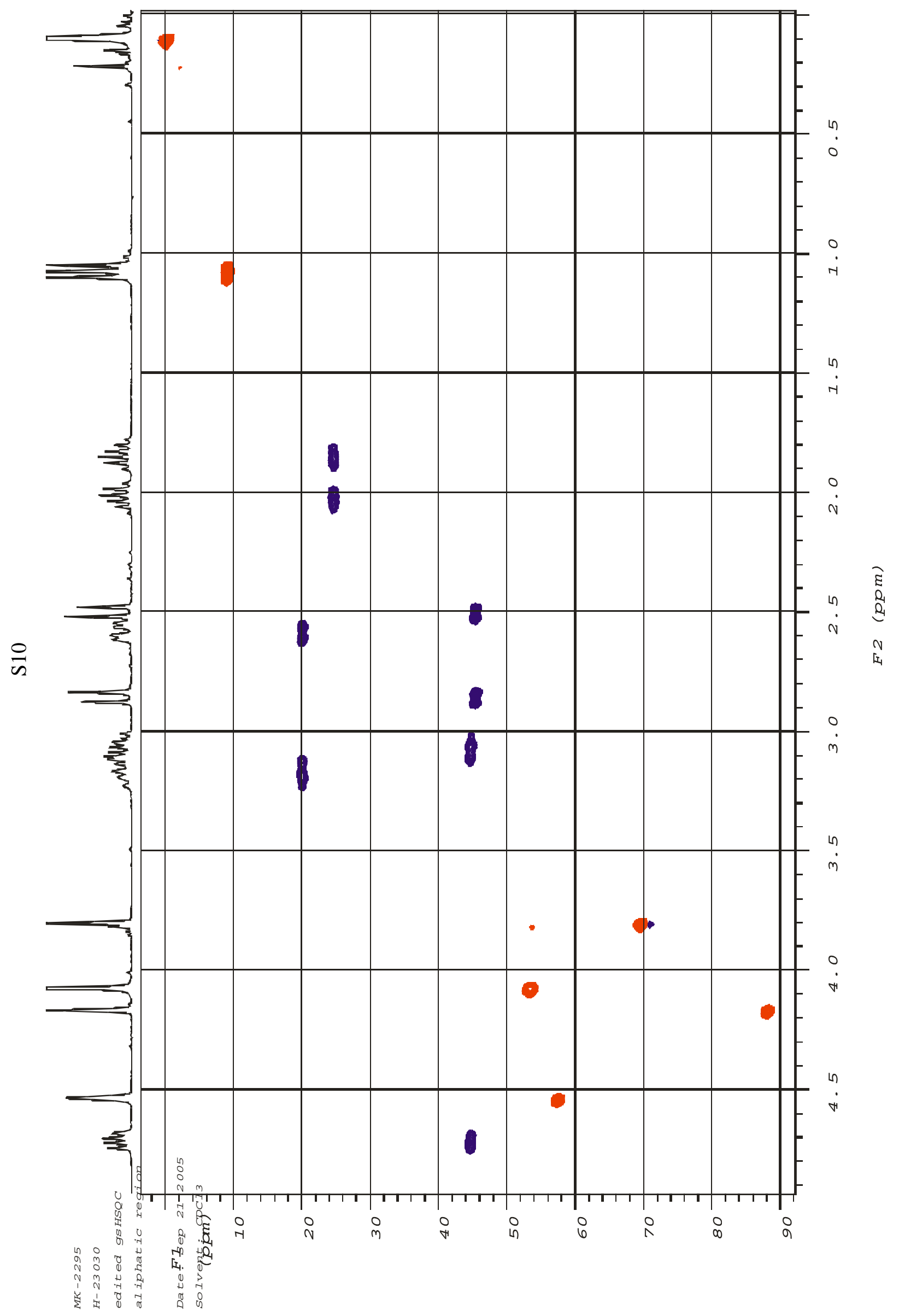




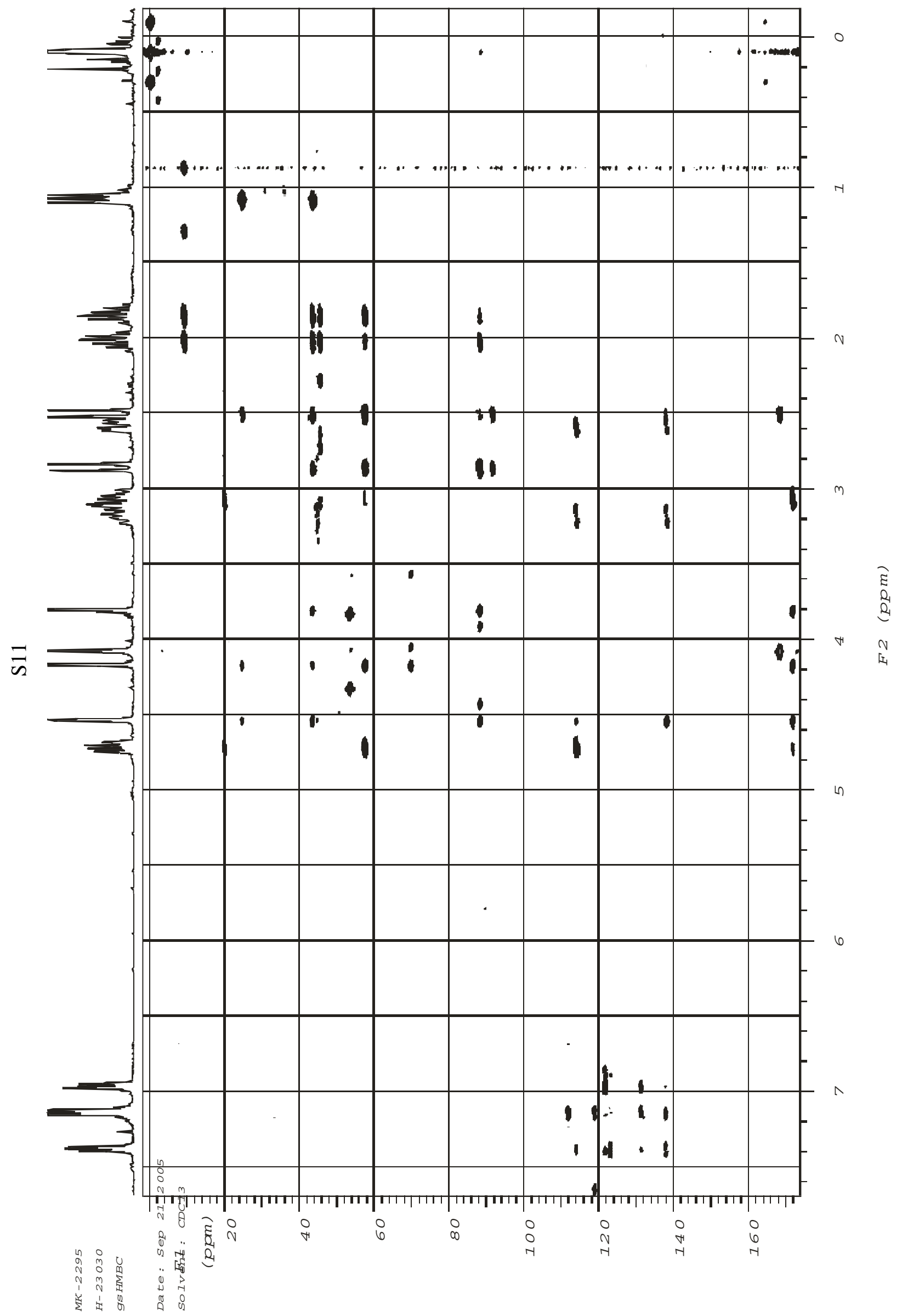




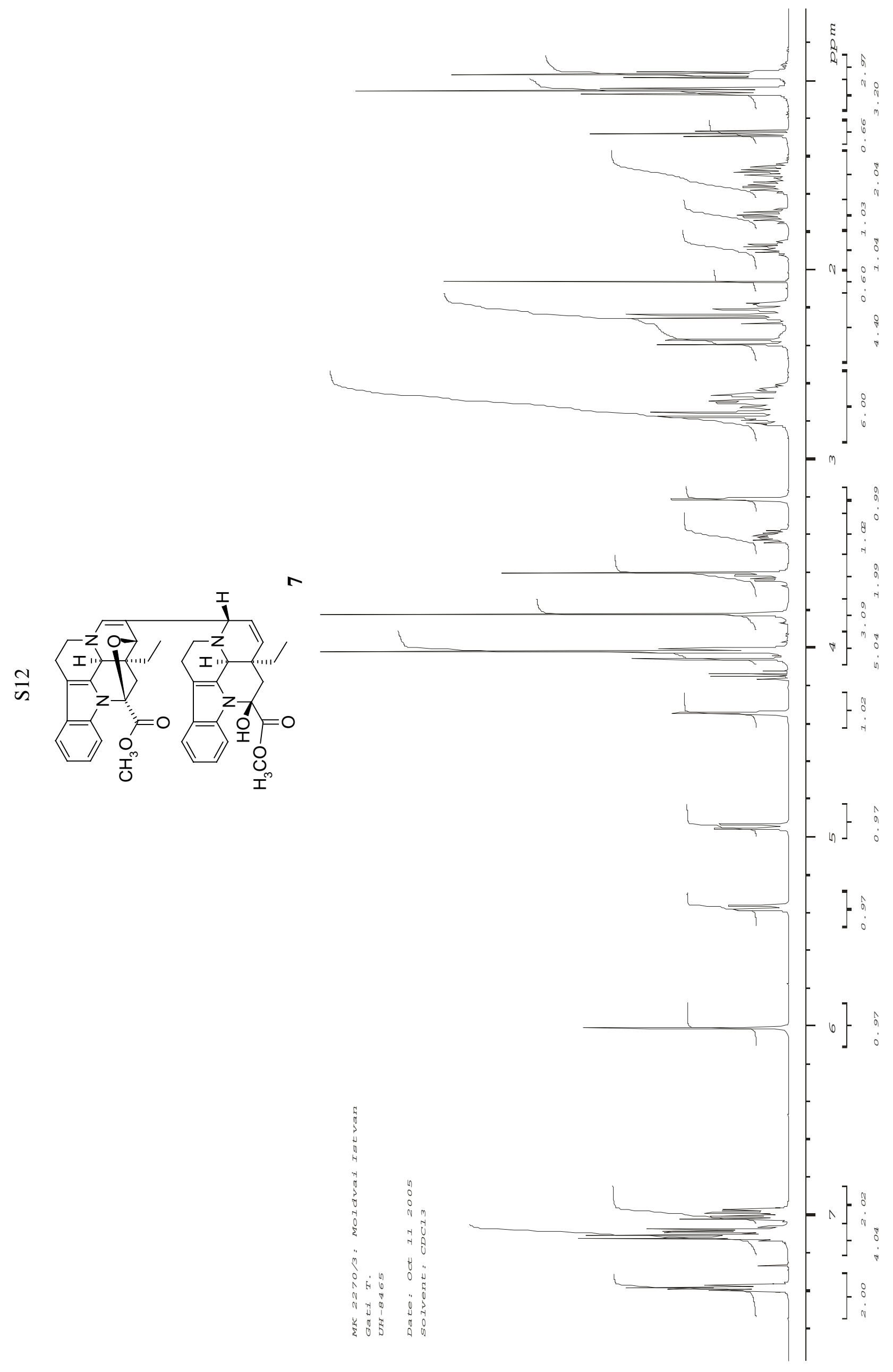




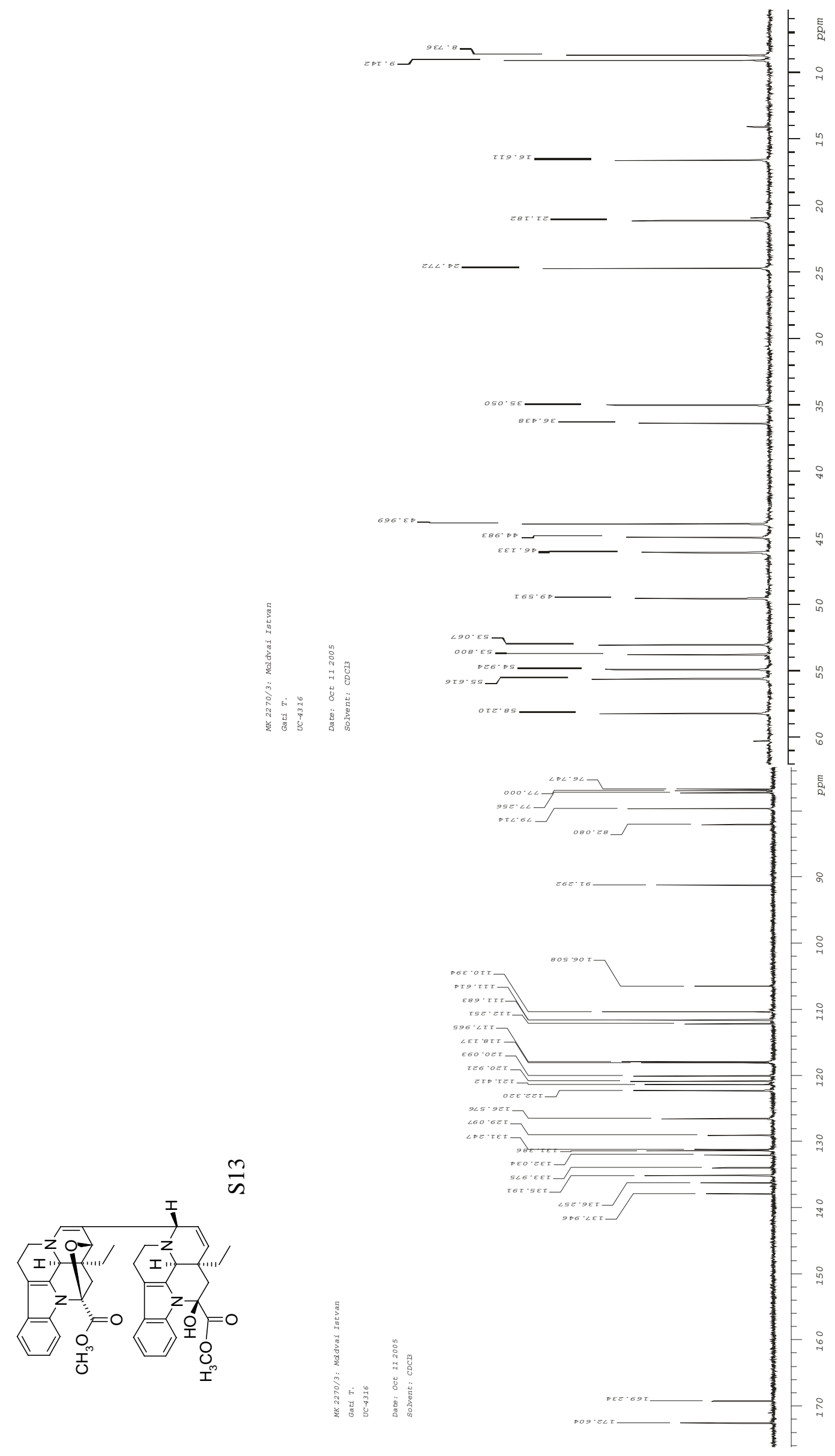




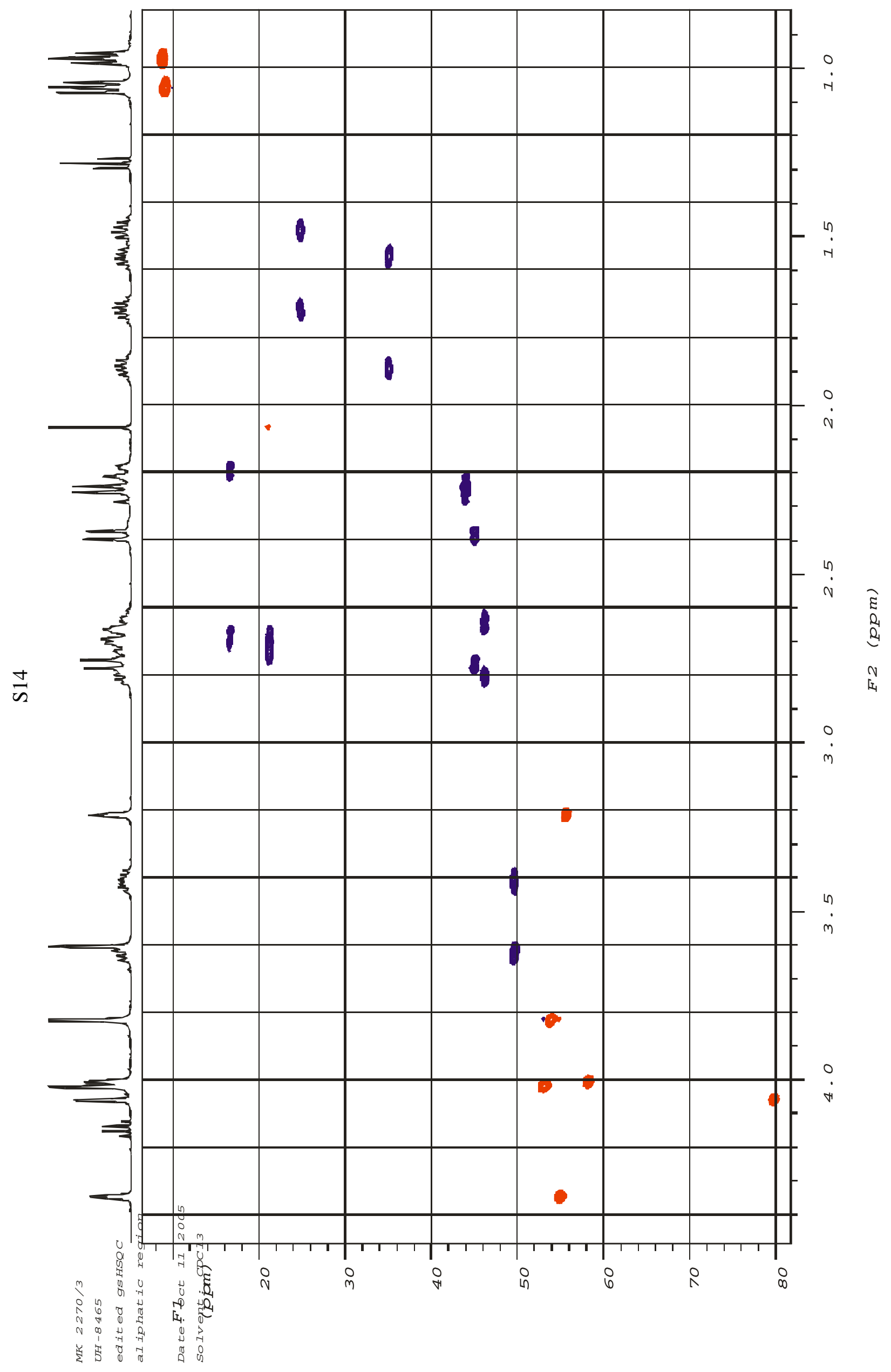




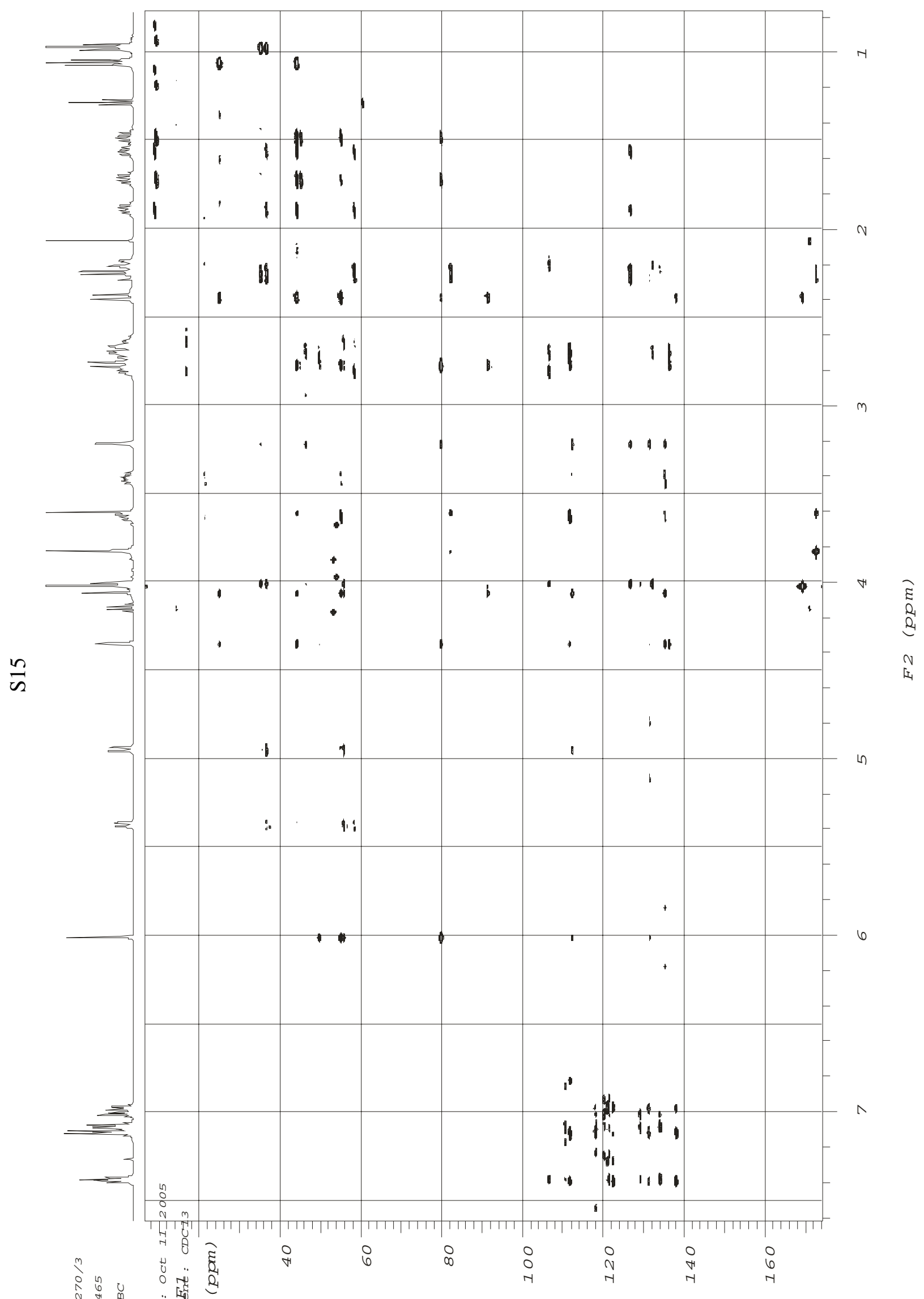




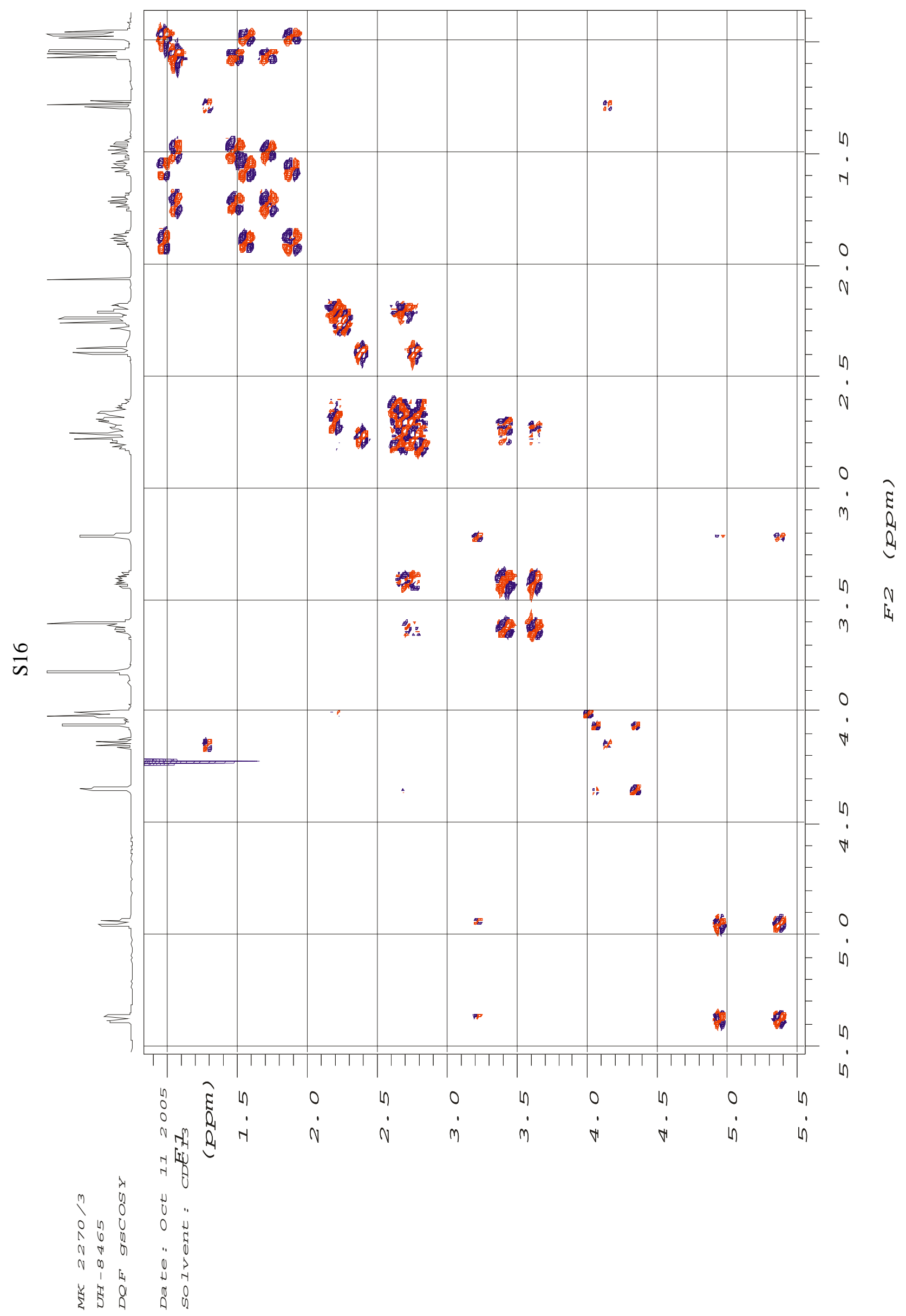




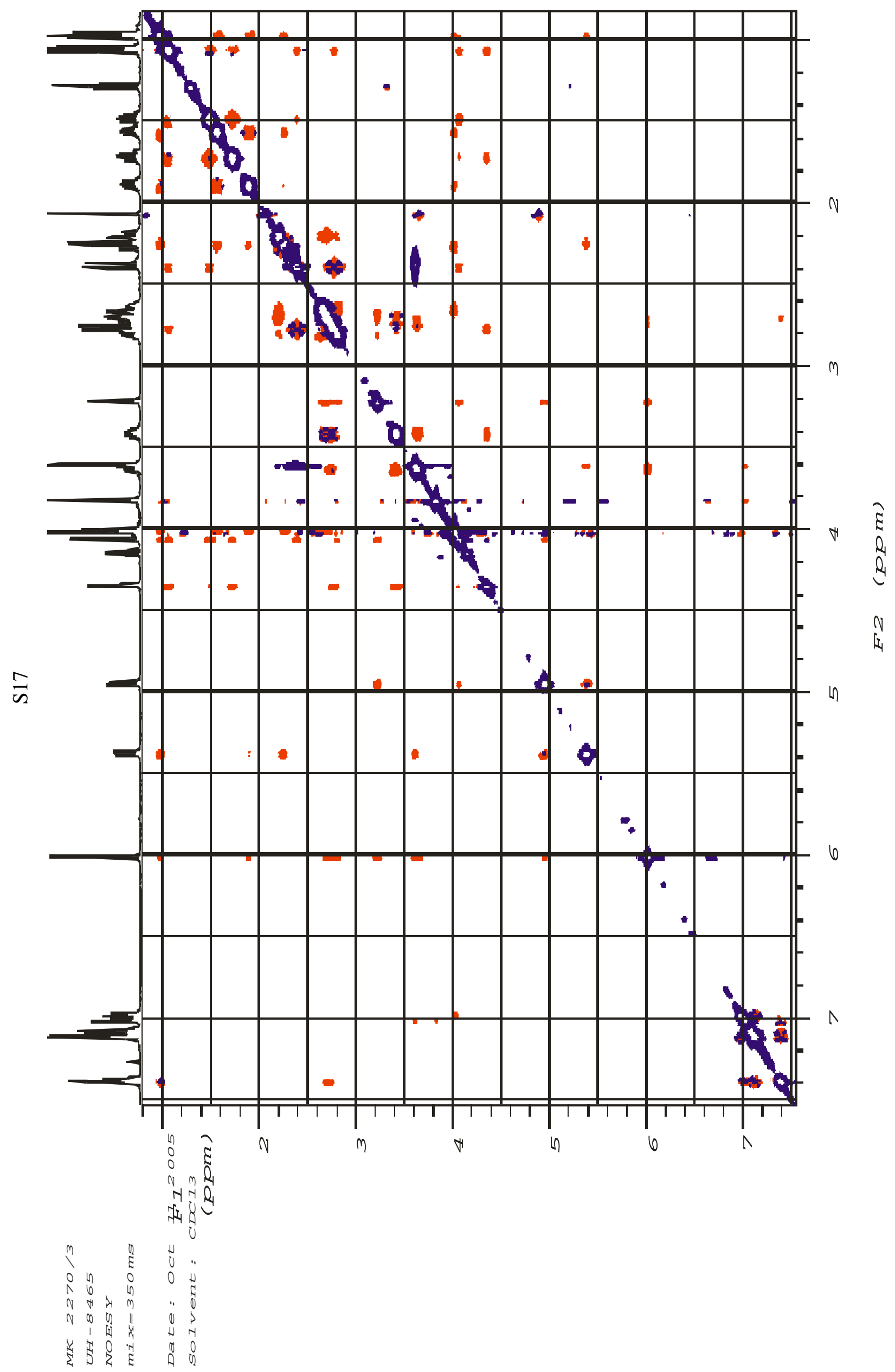




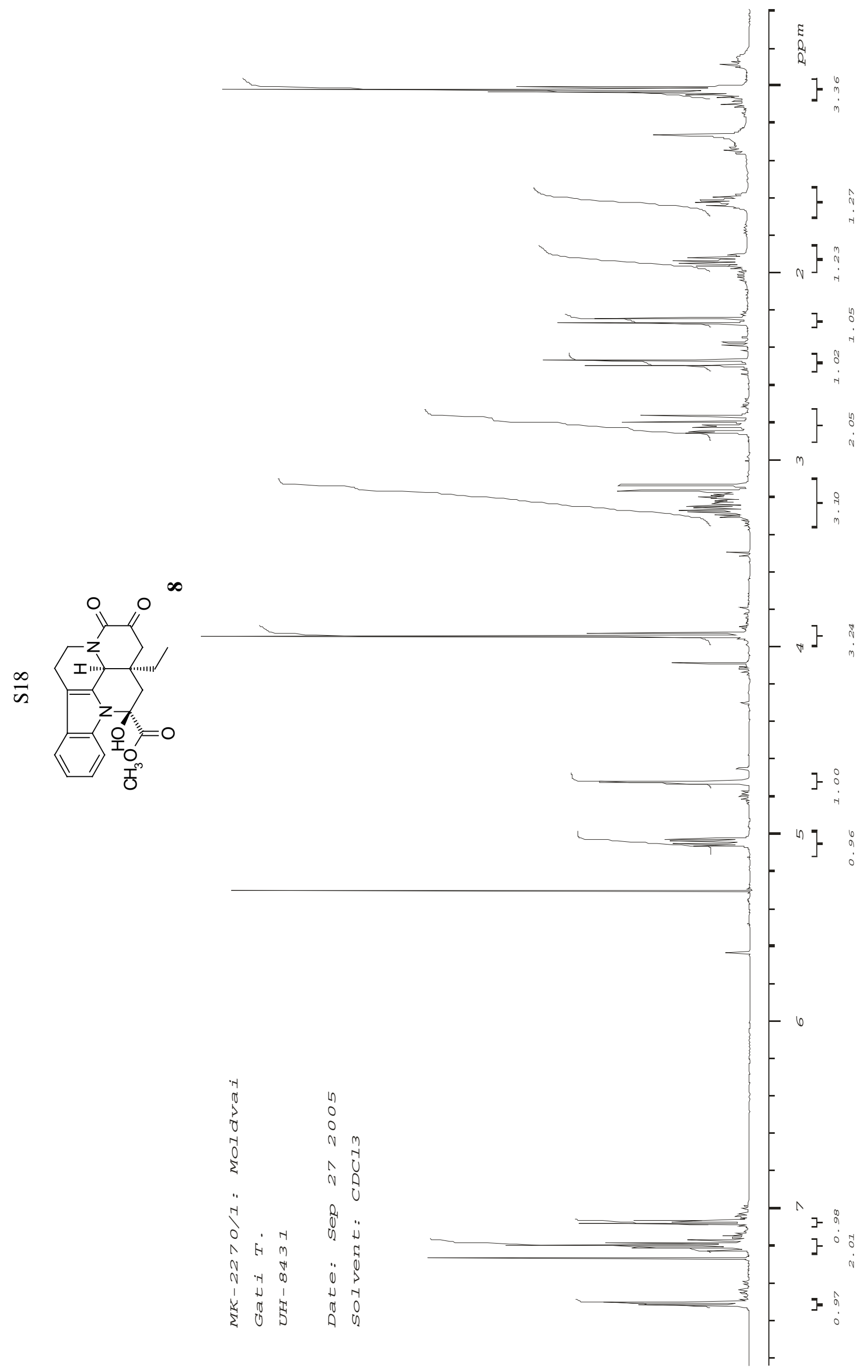



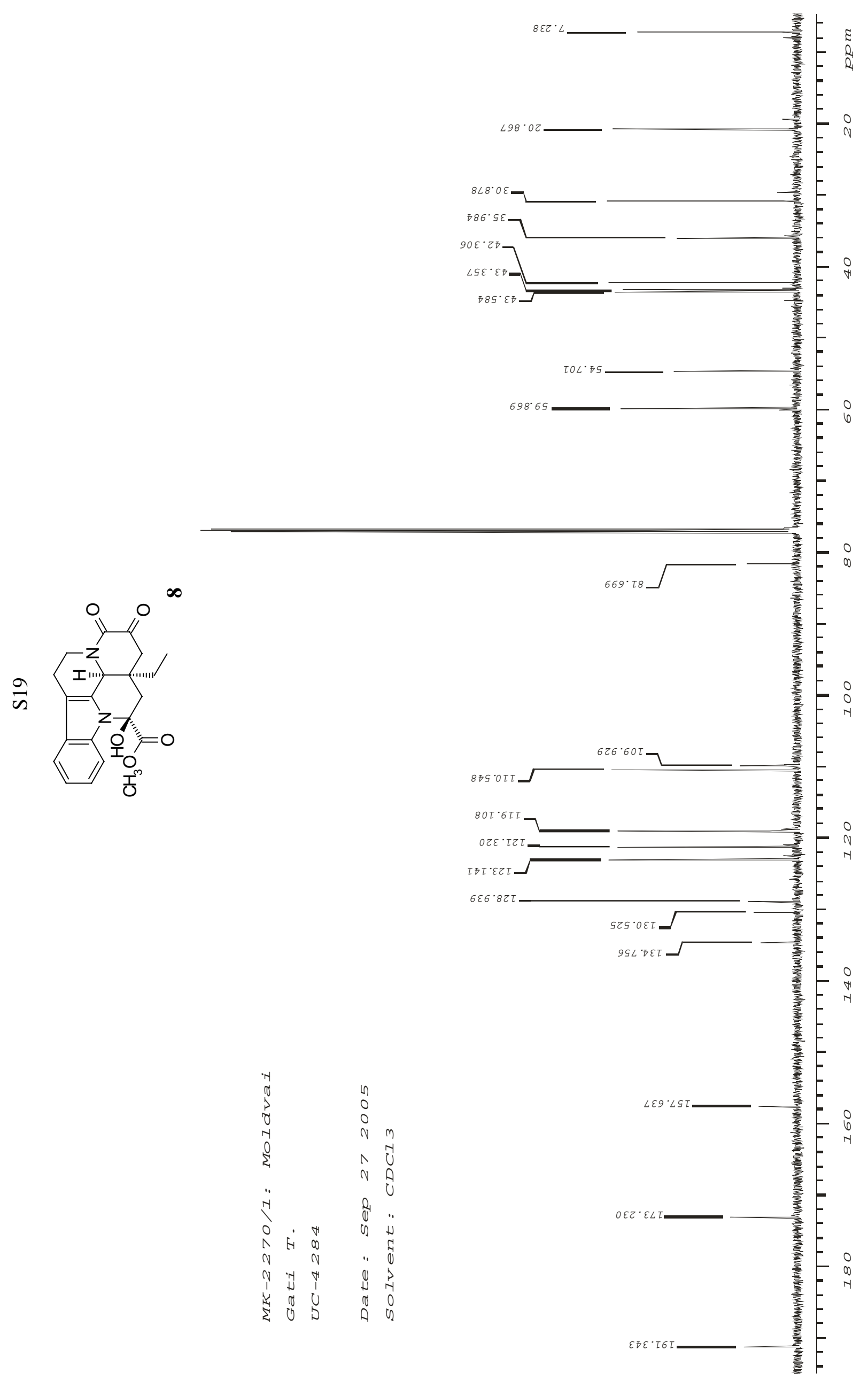


$$
\text { . }
$$




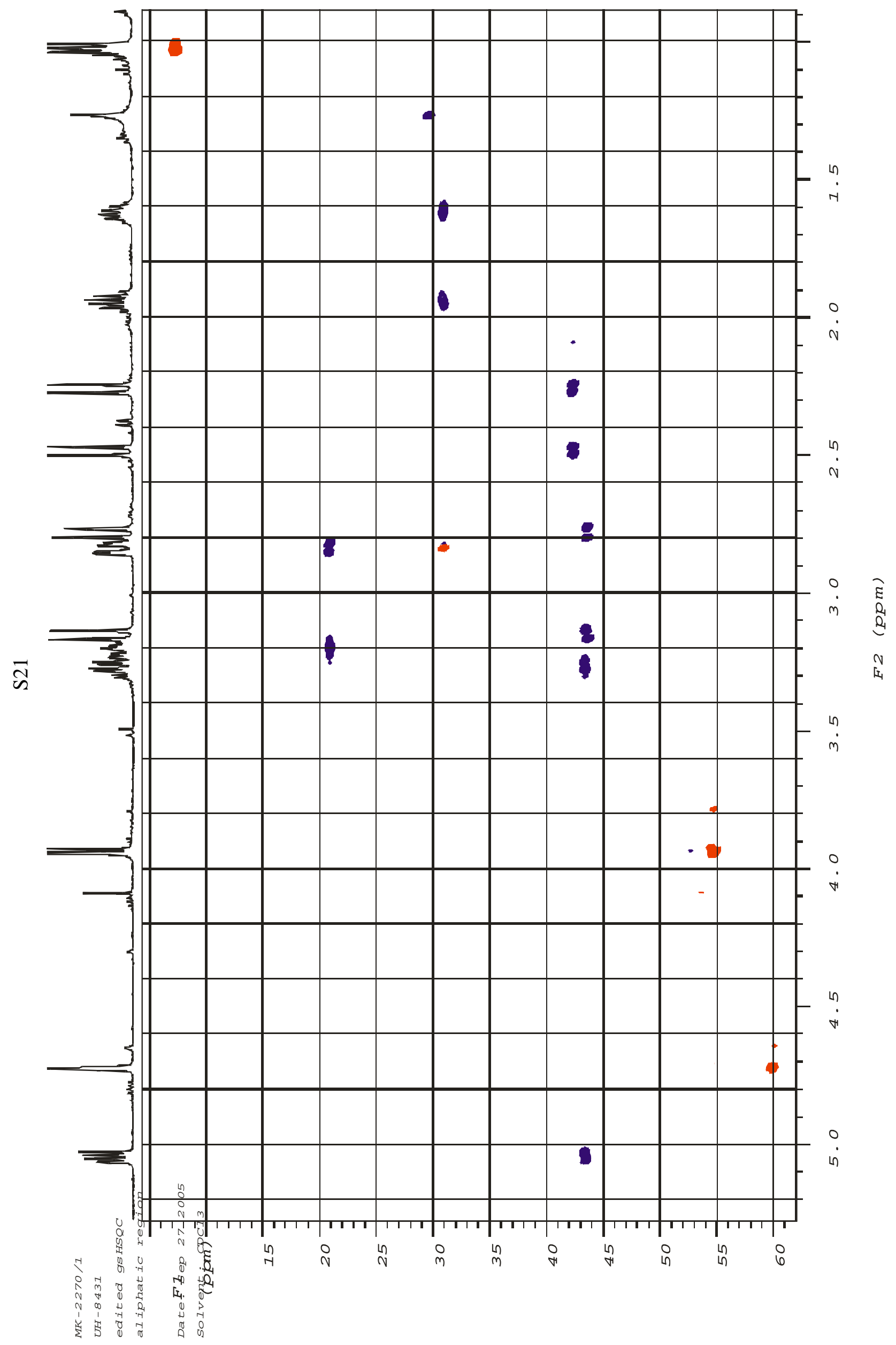




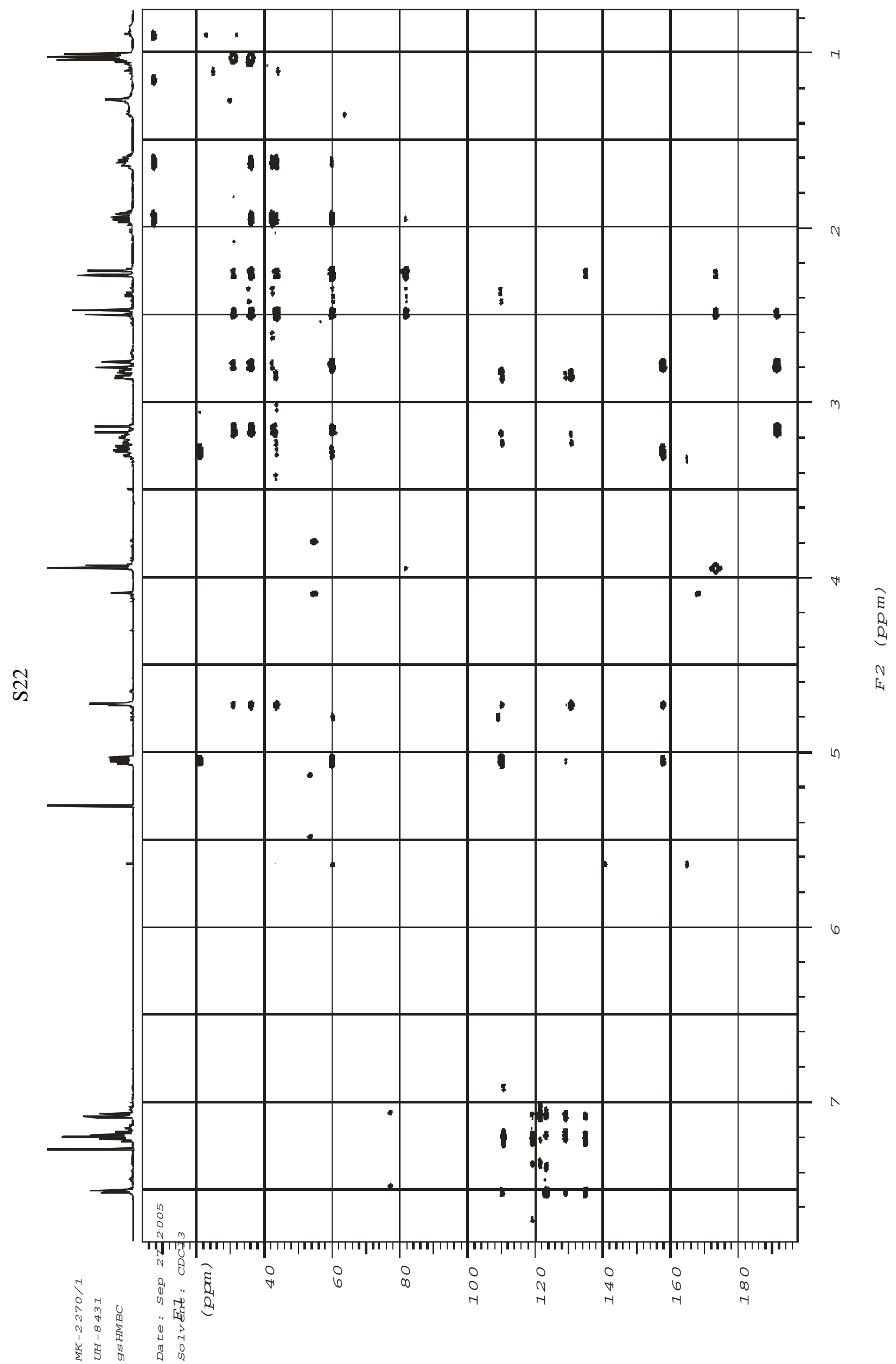




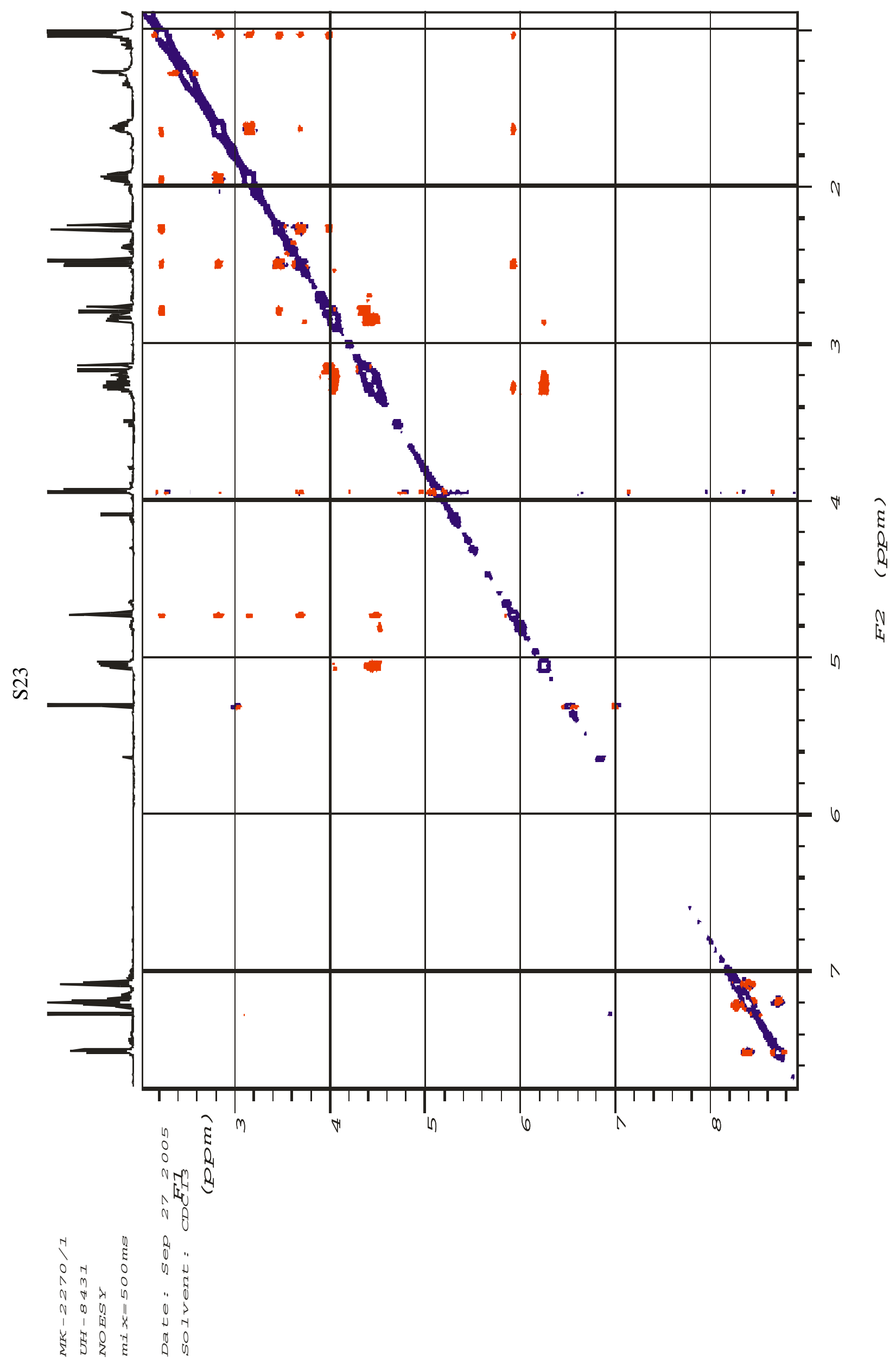




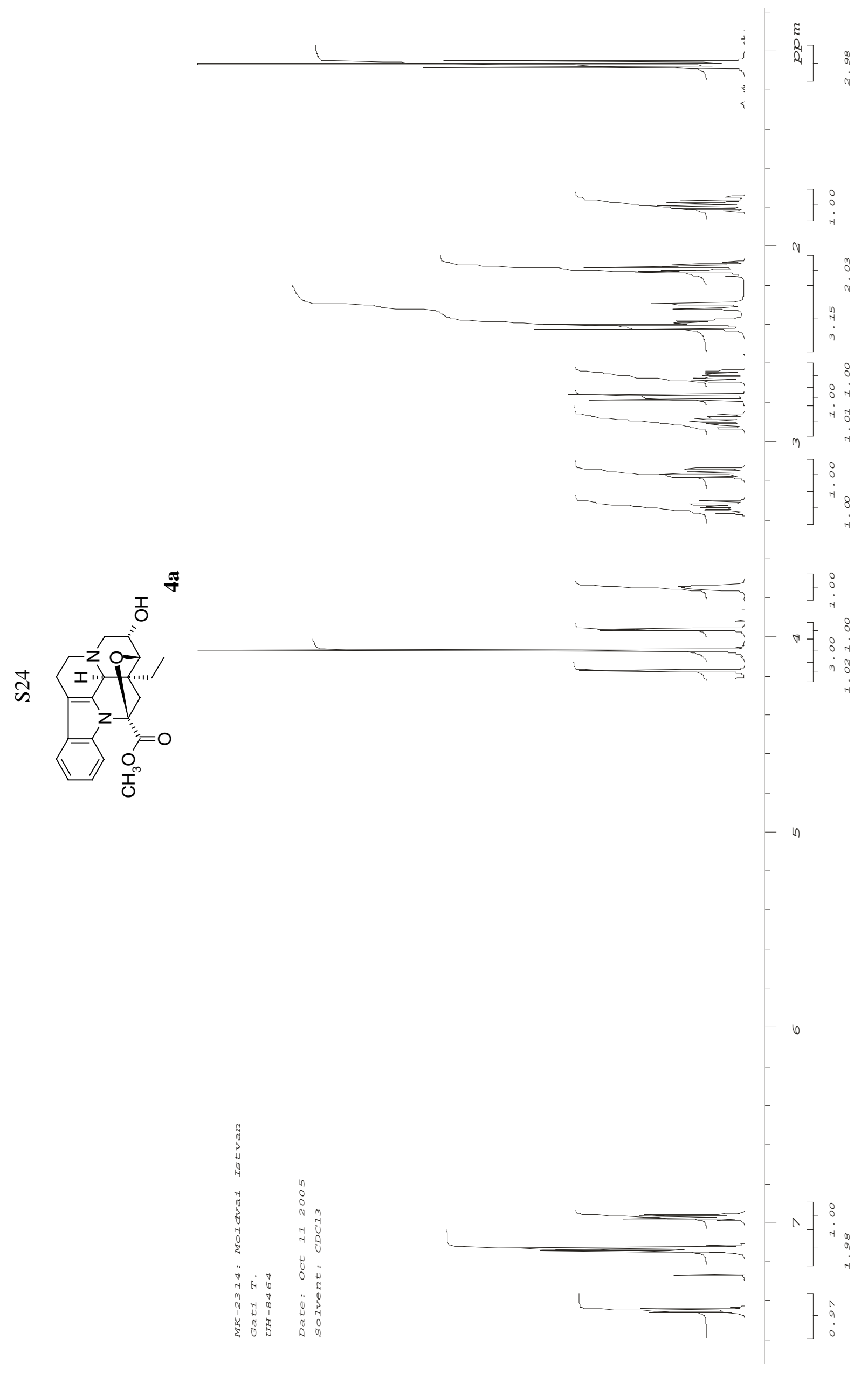



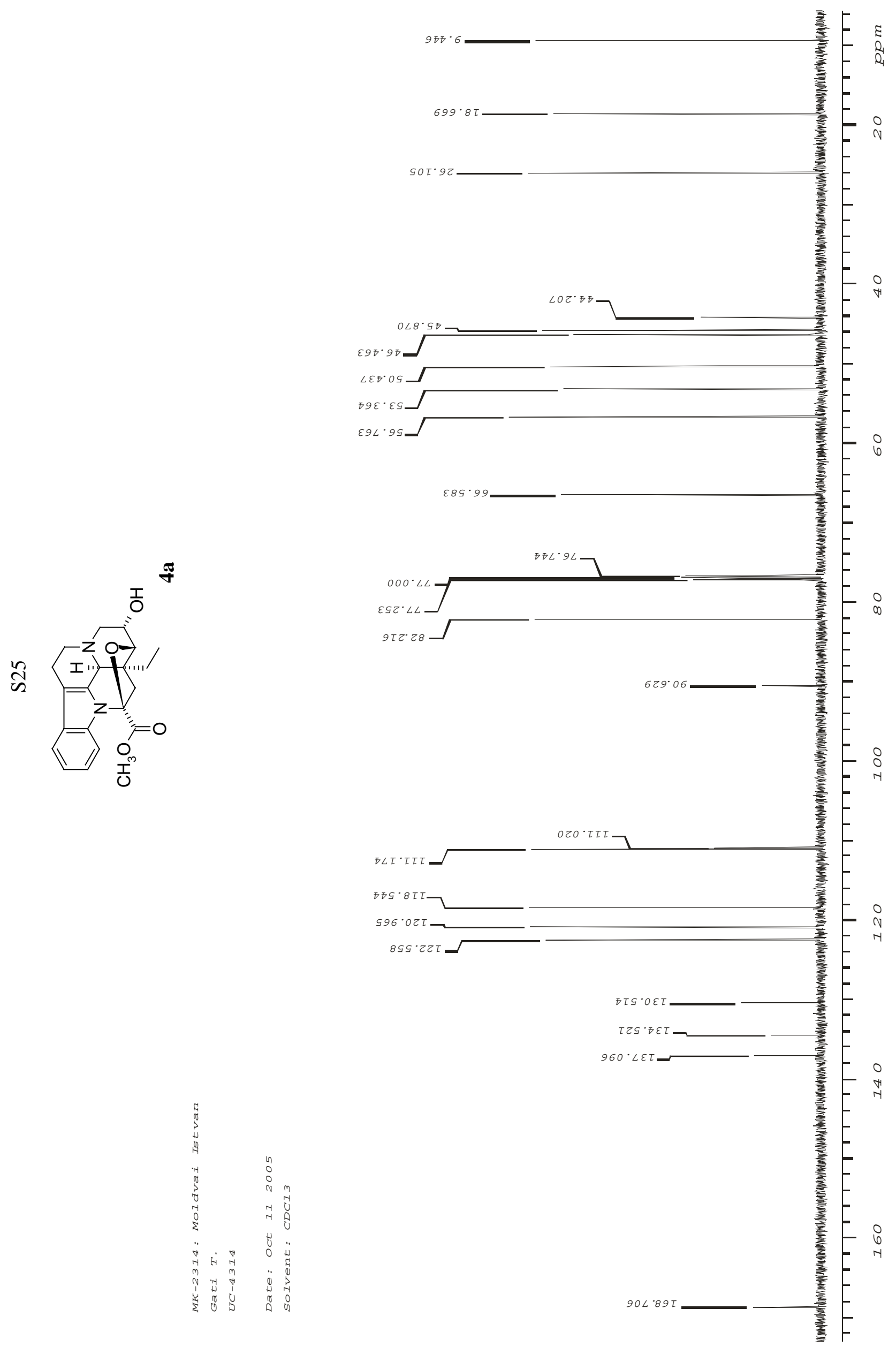


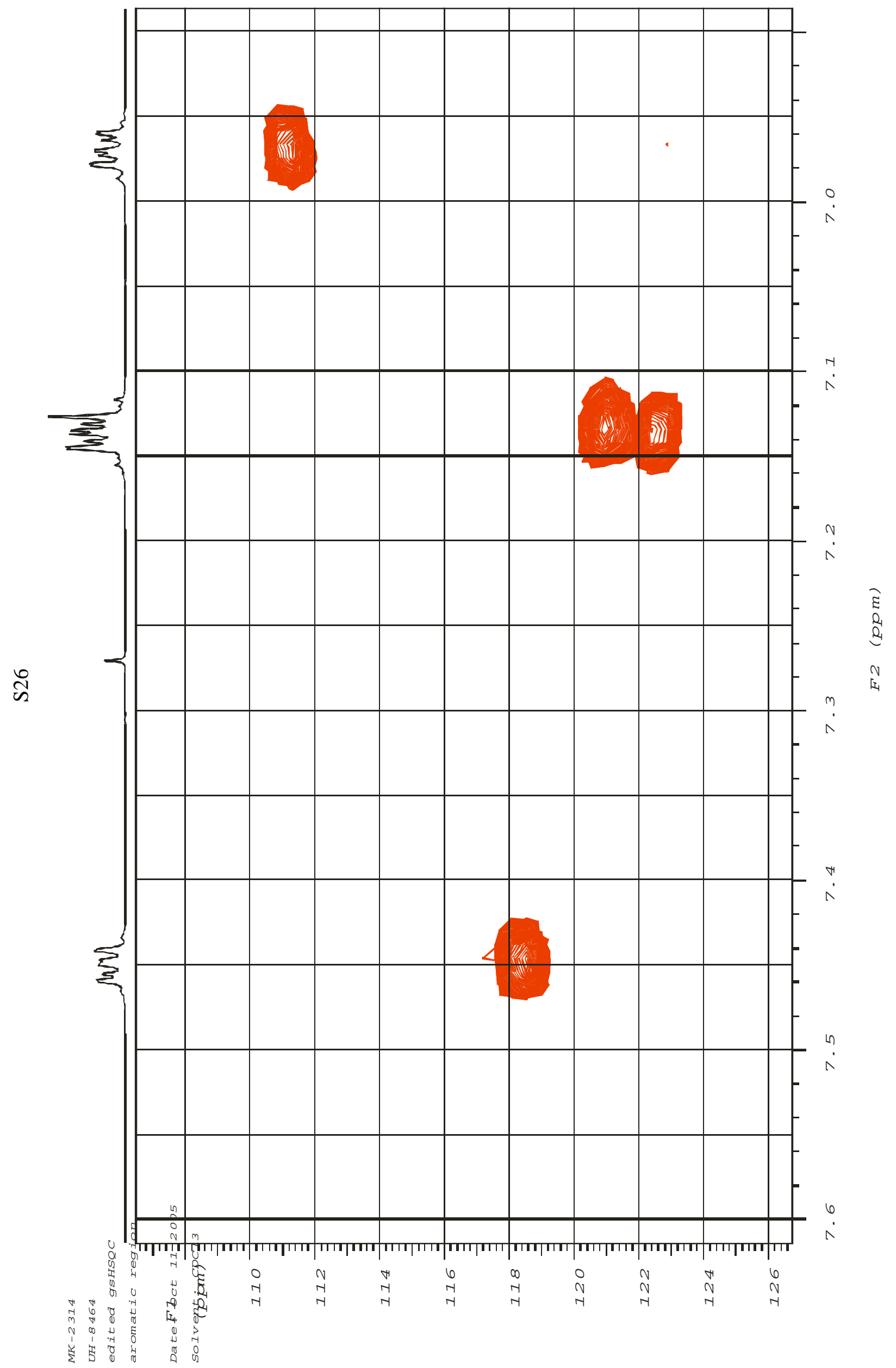




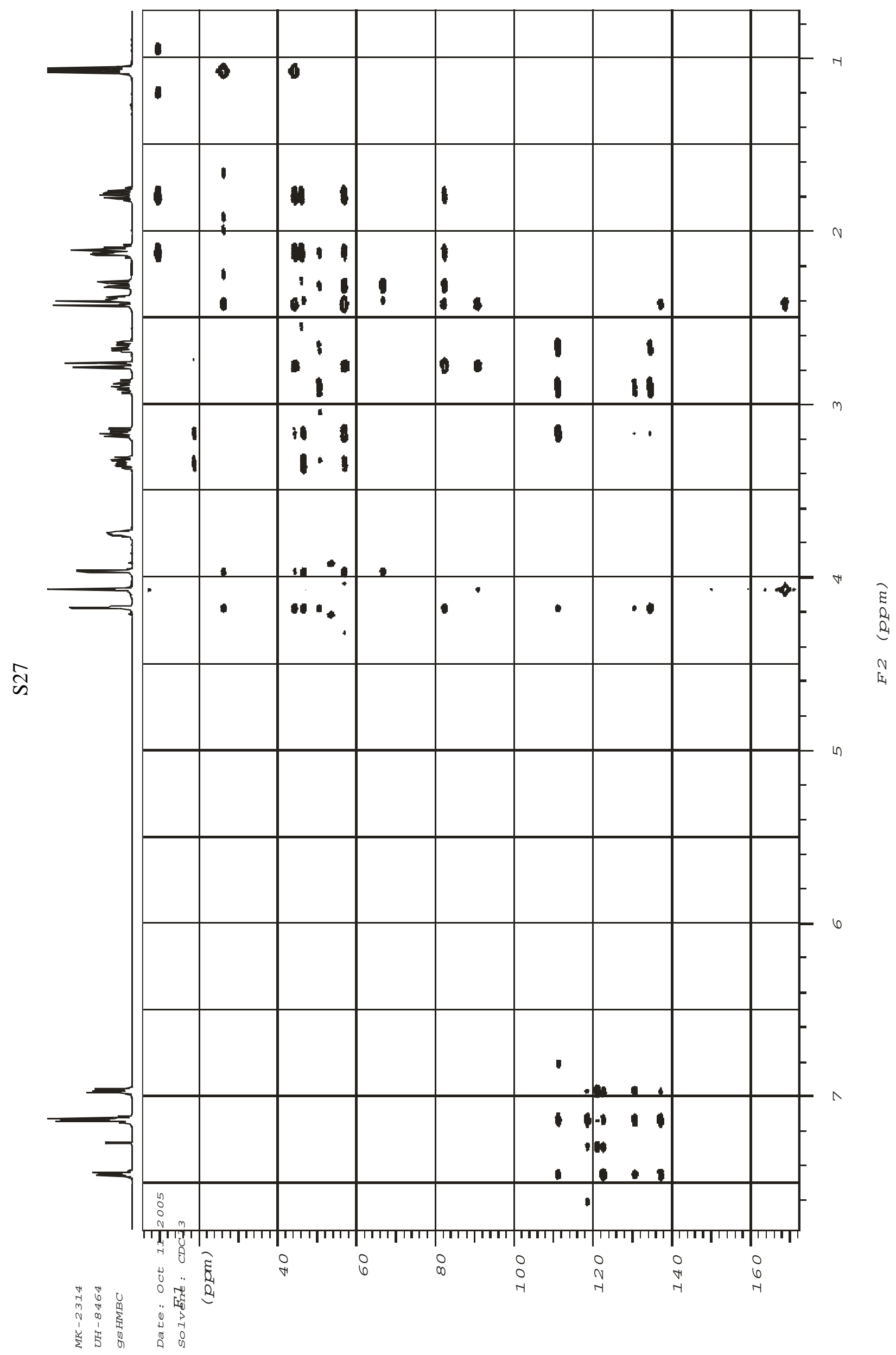




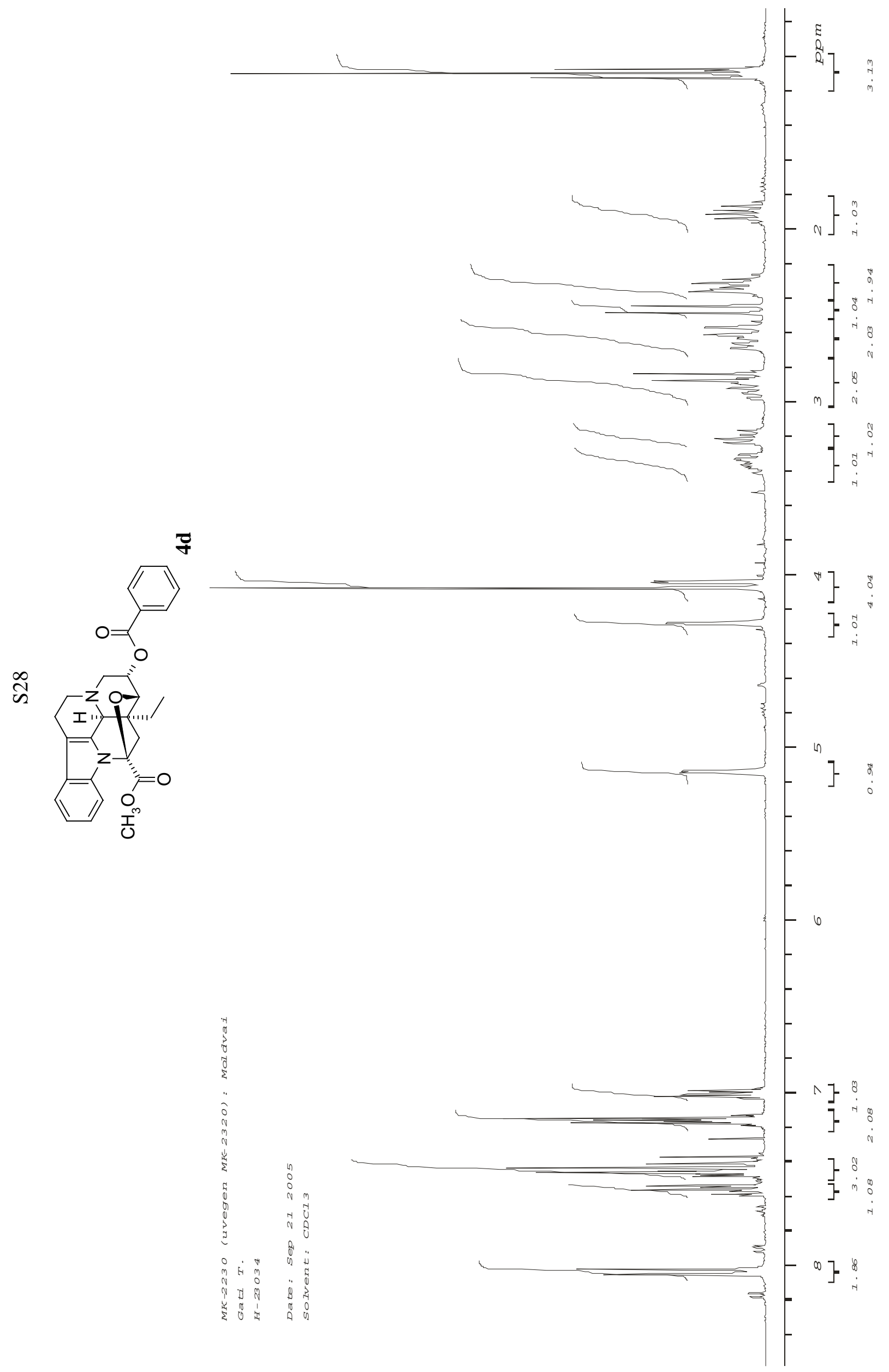



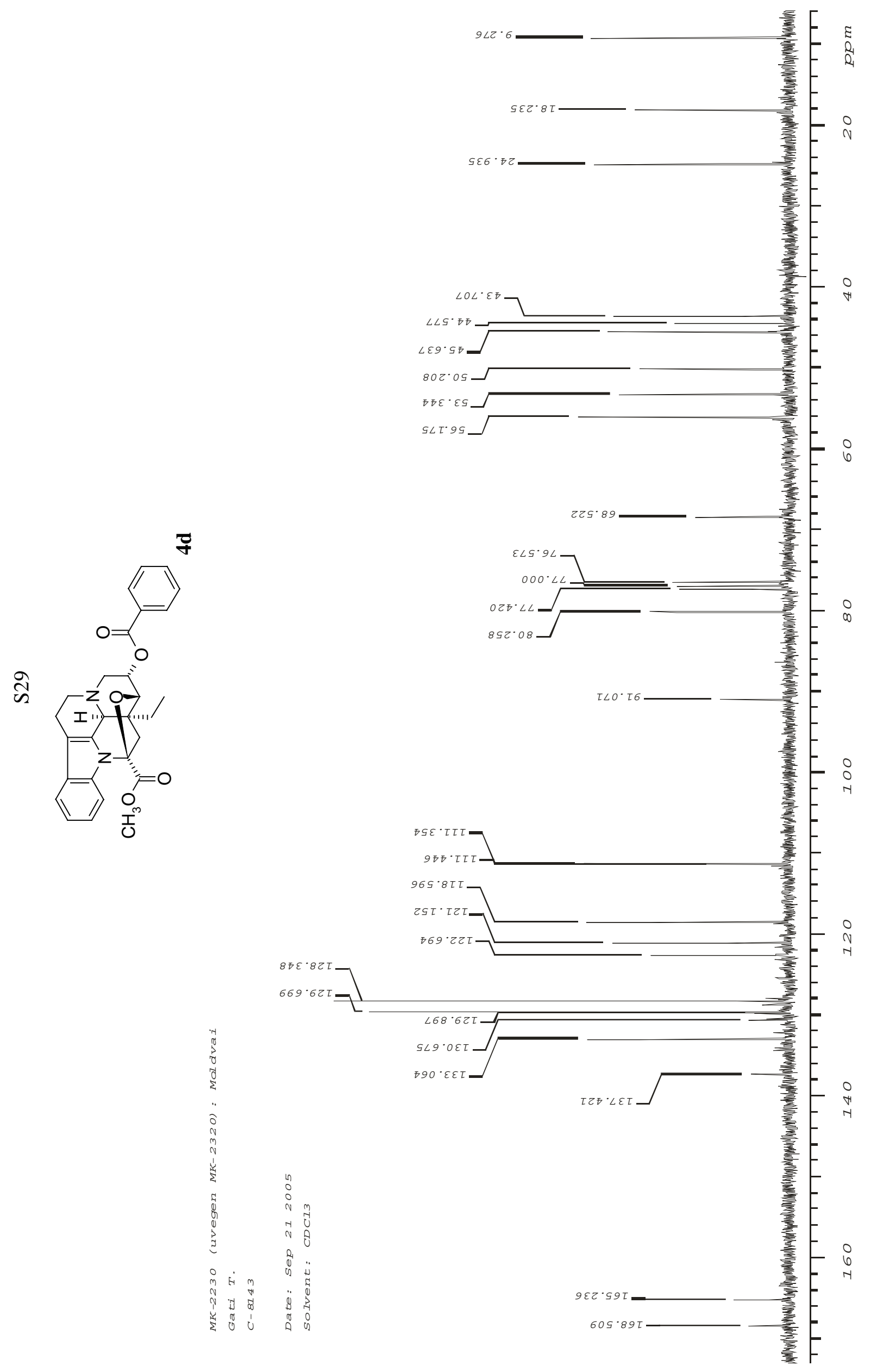


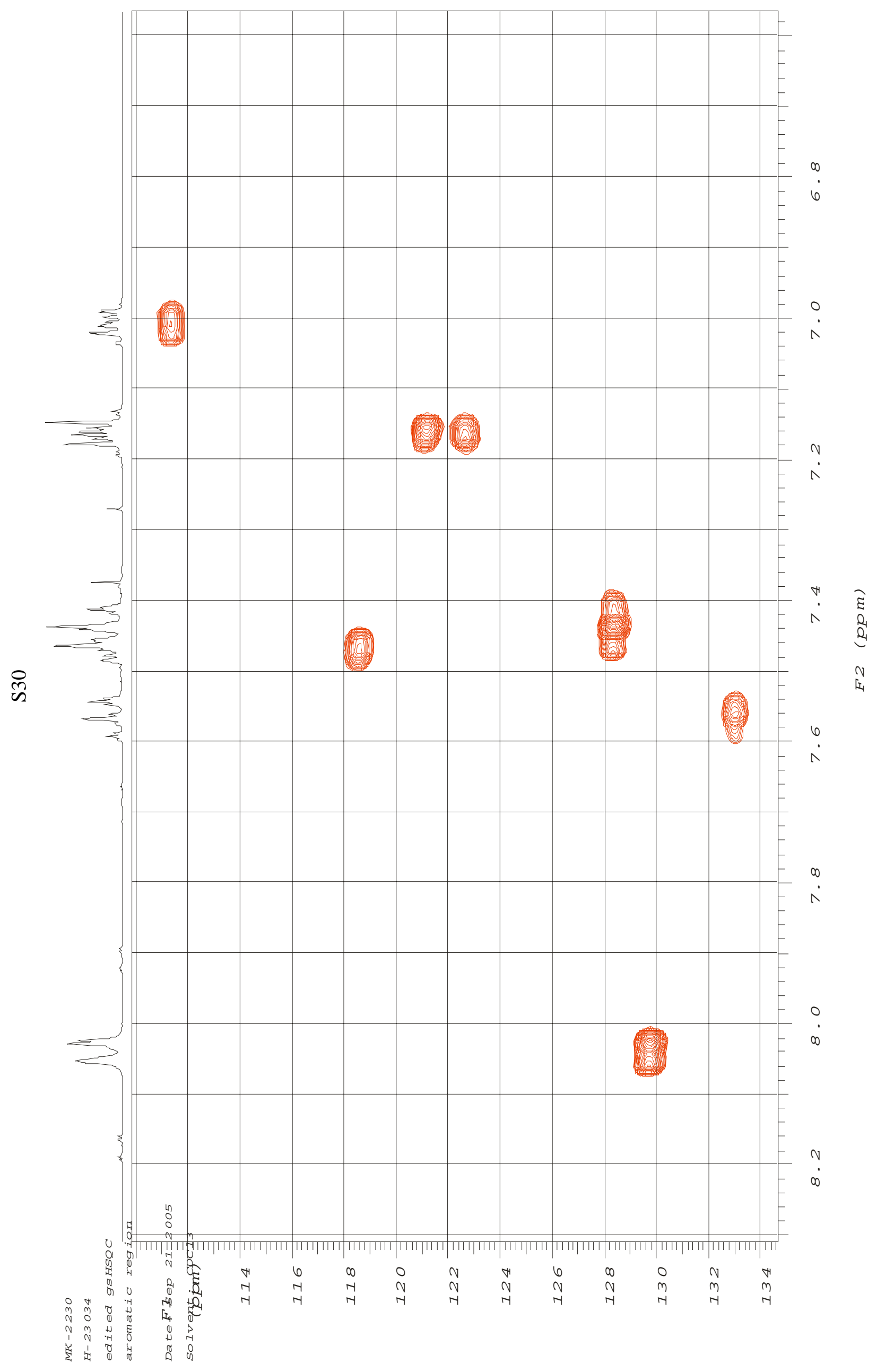




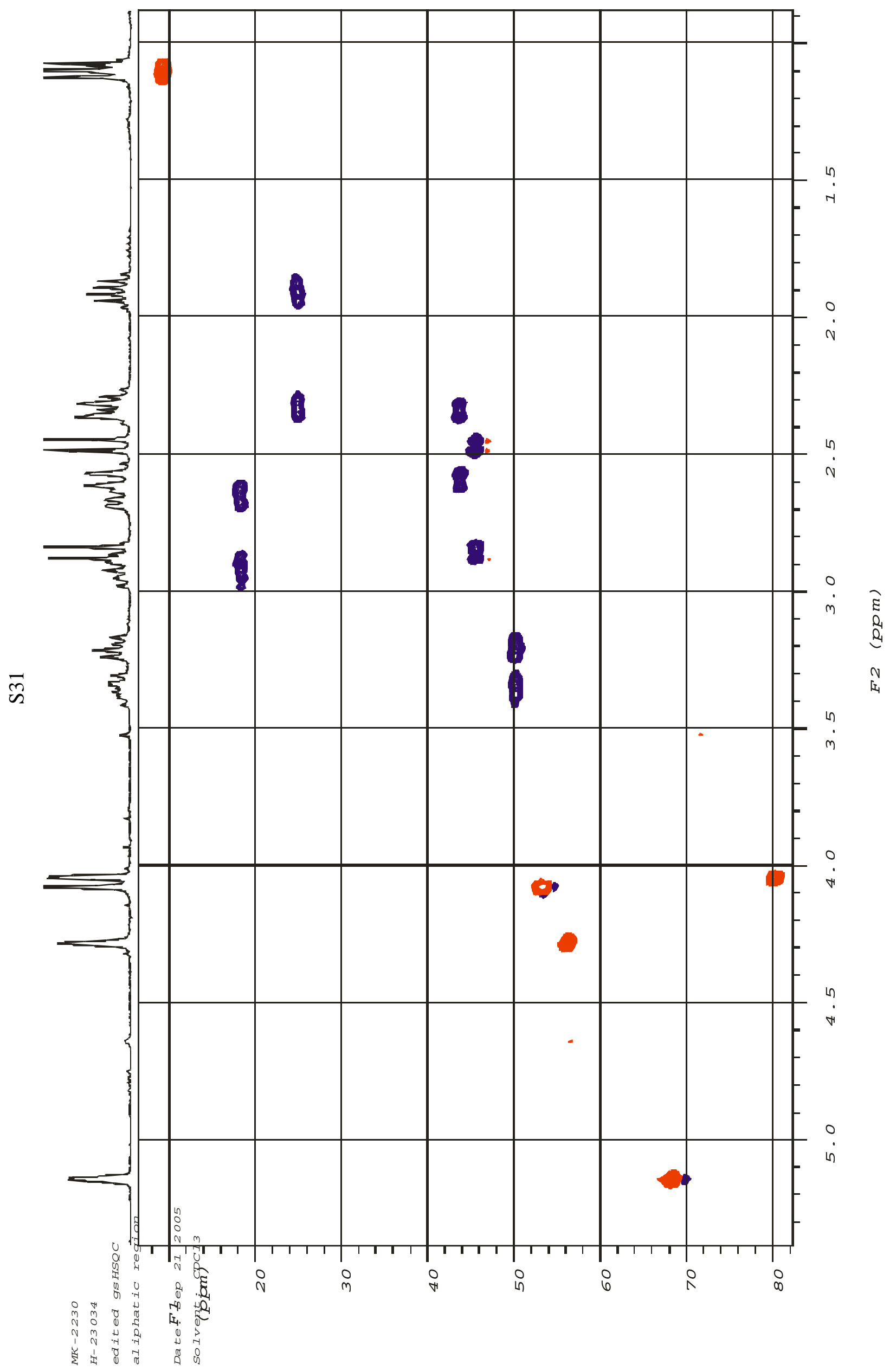




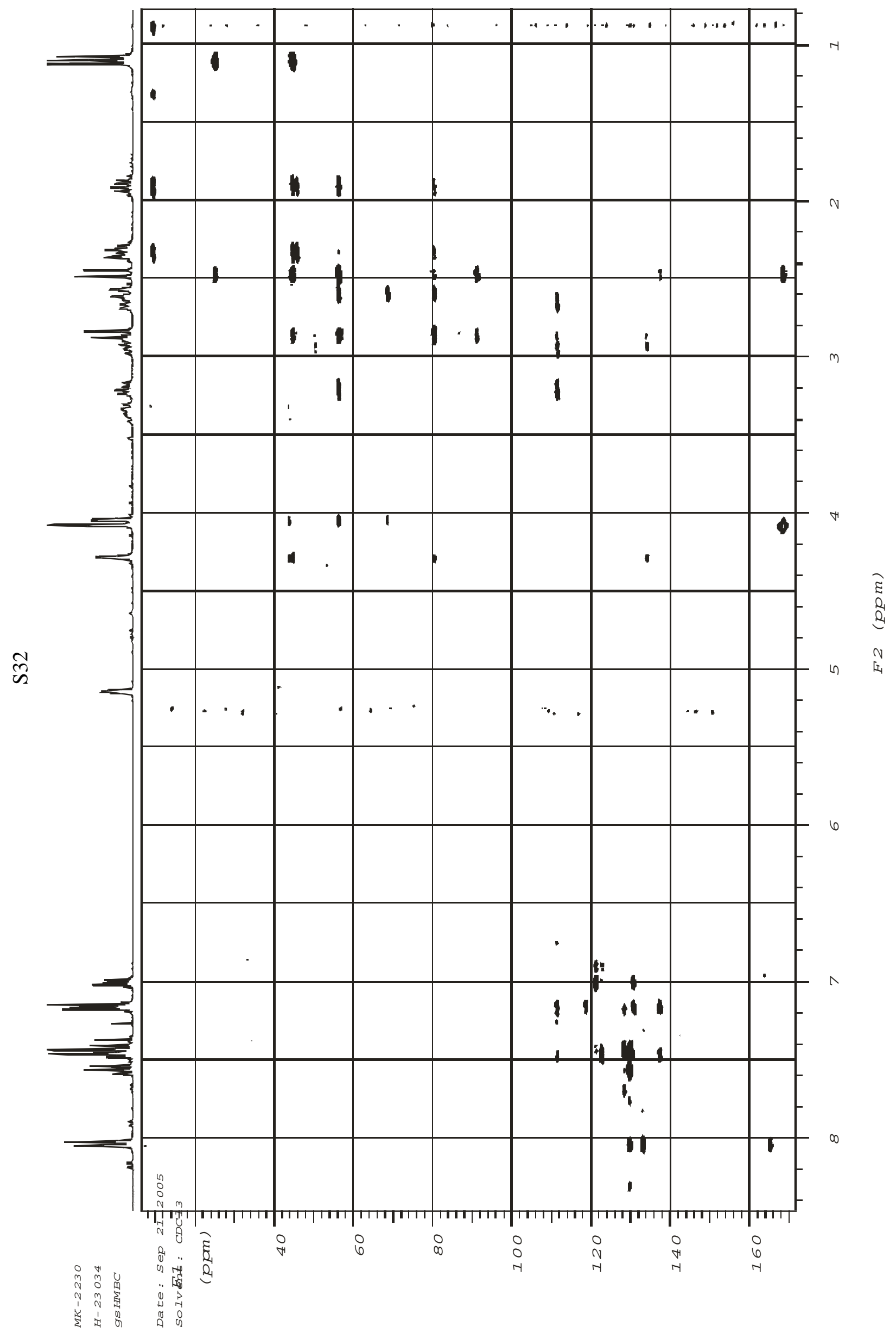




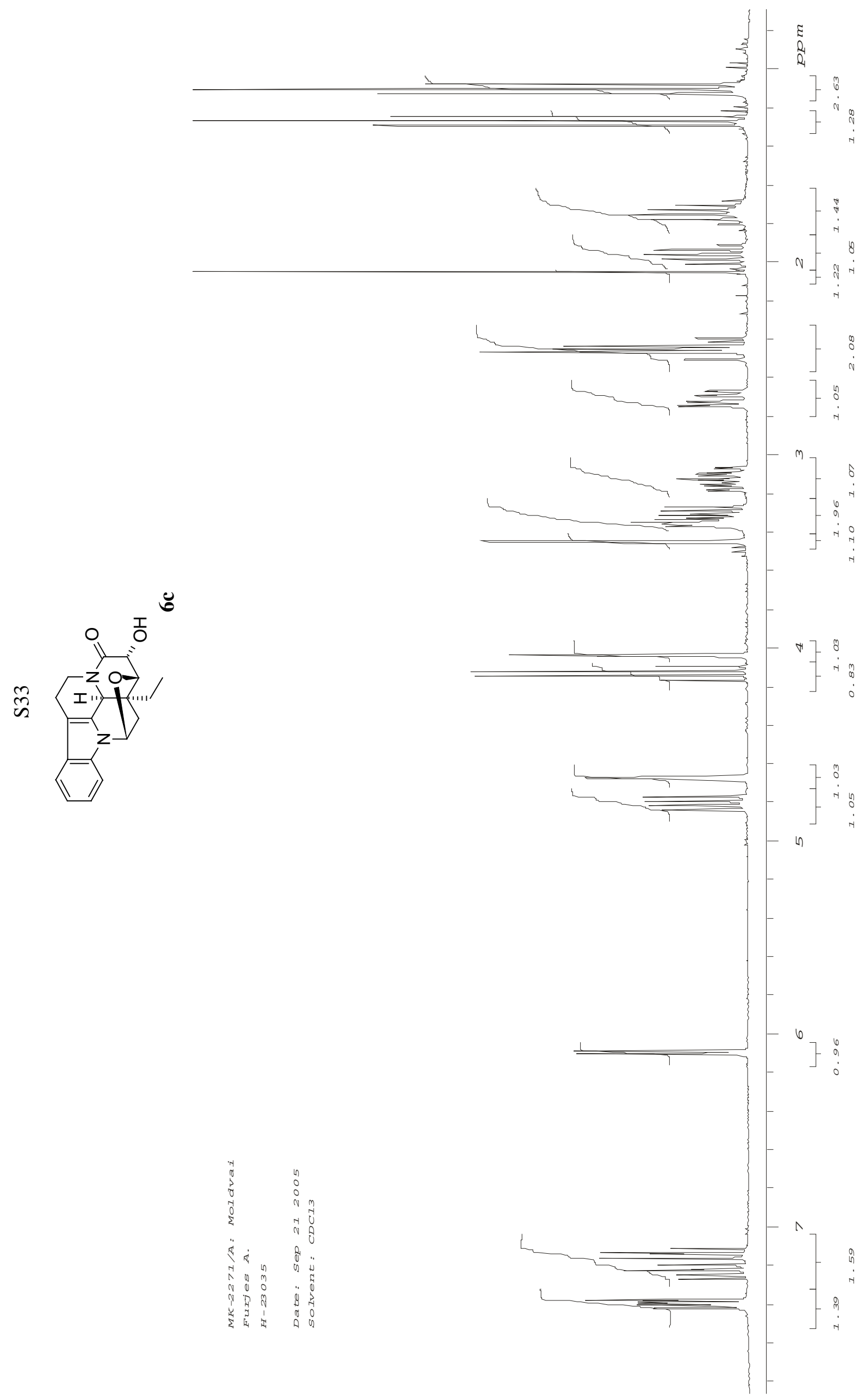



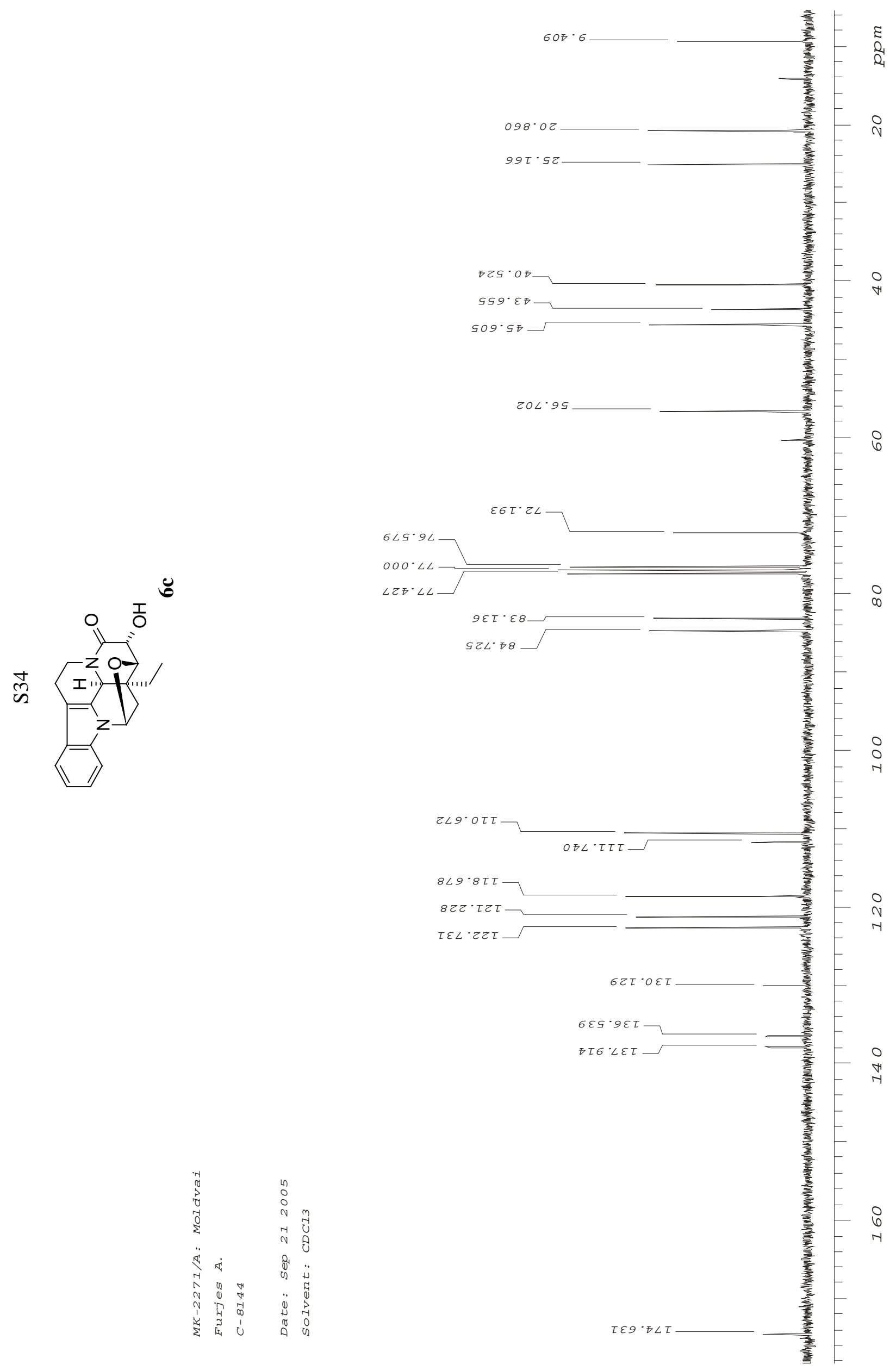


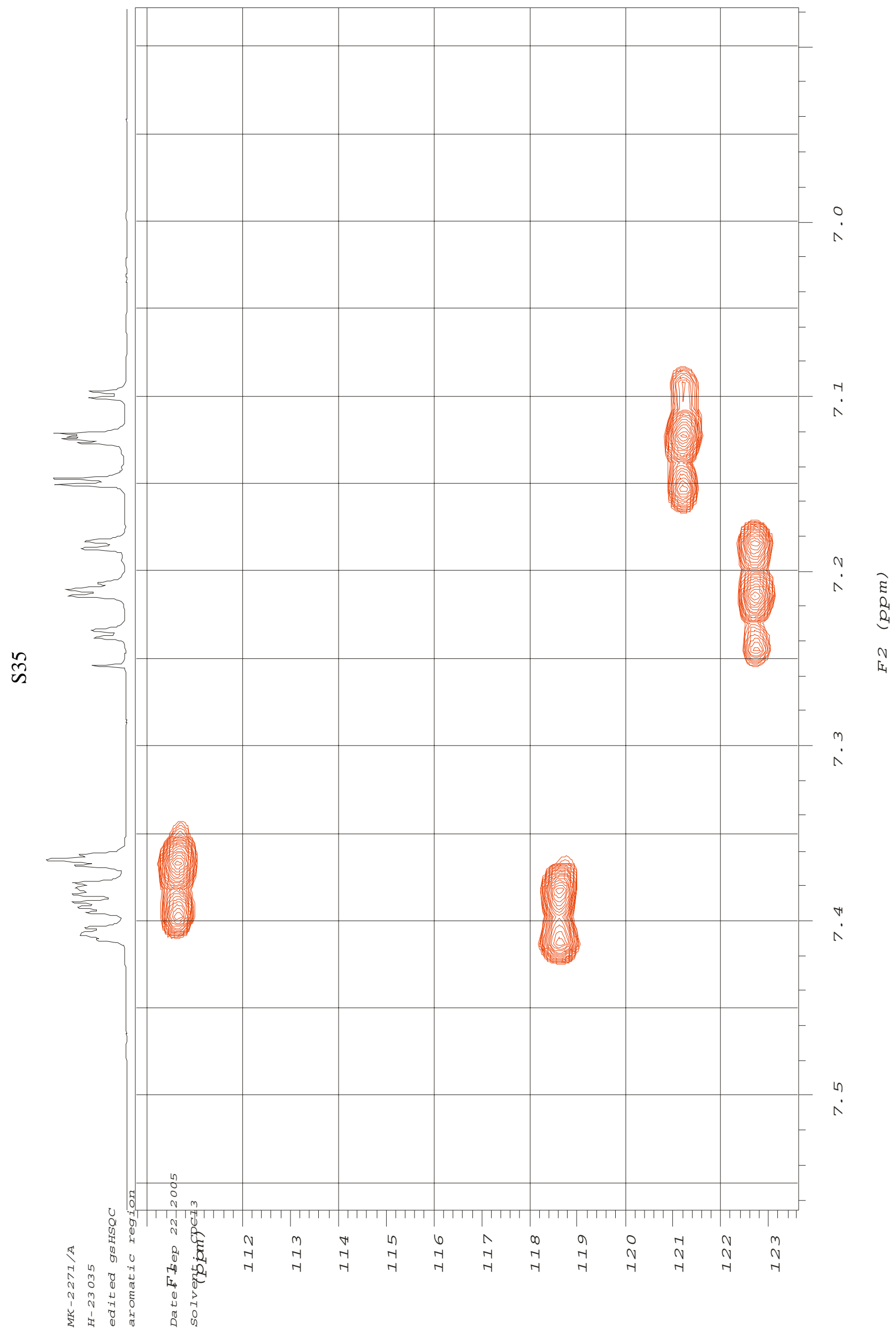




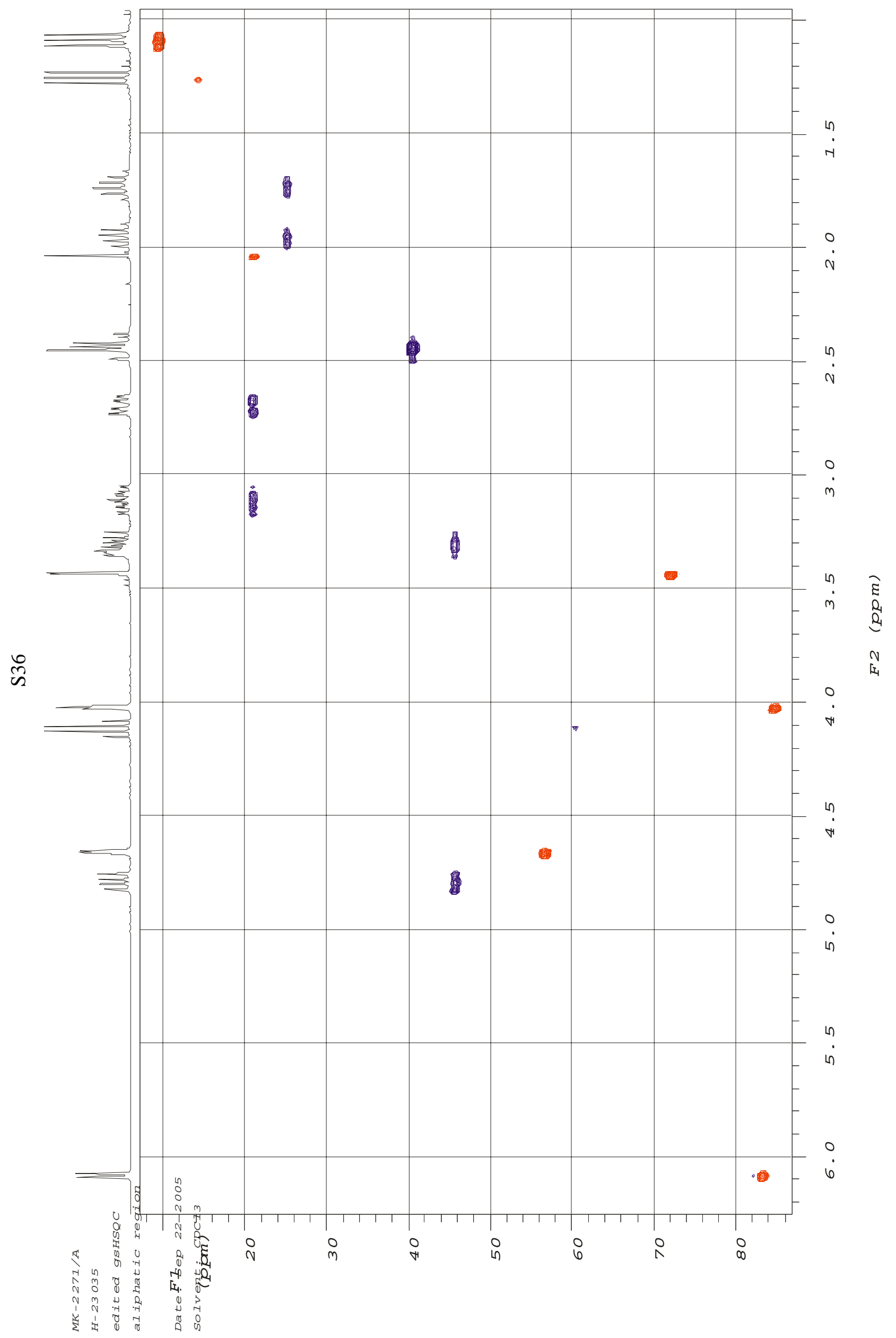




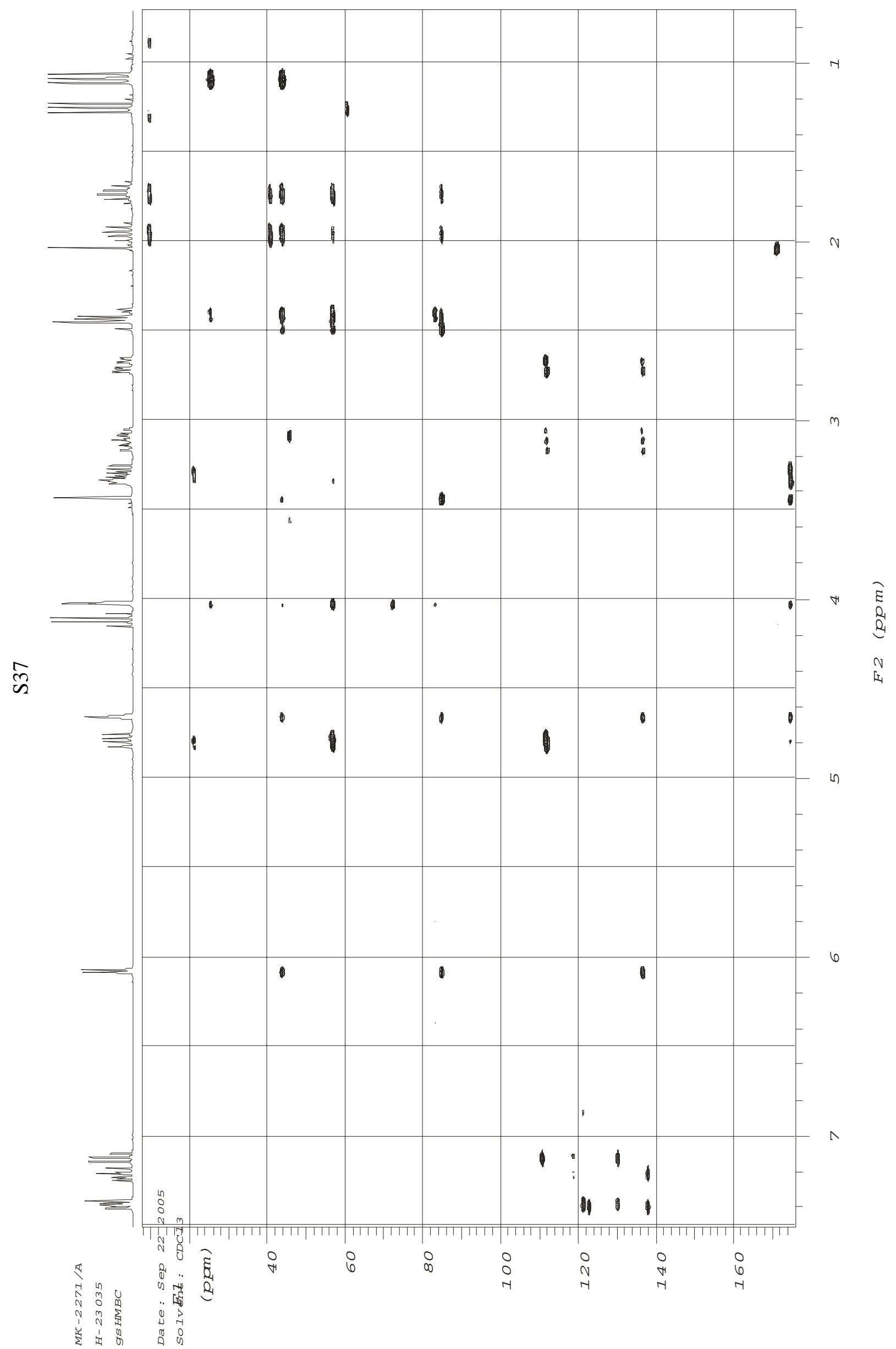




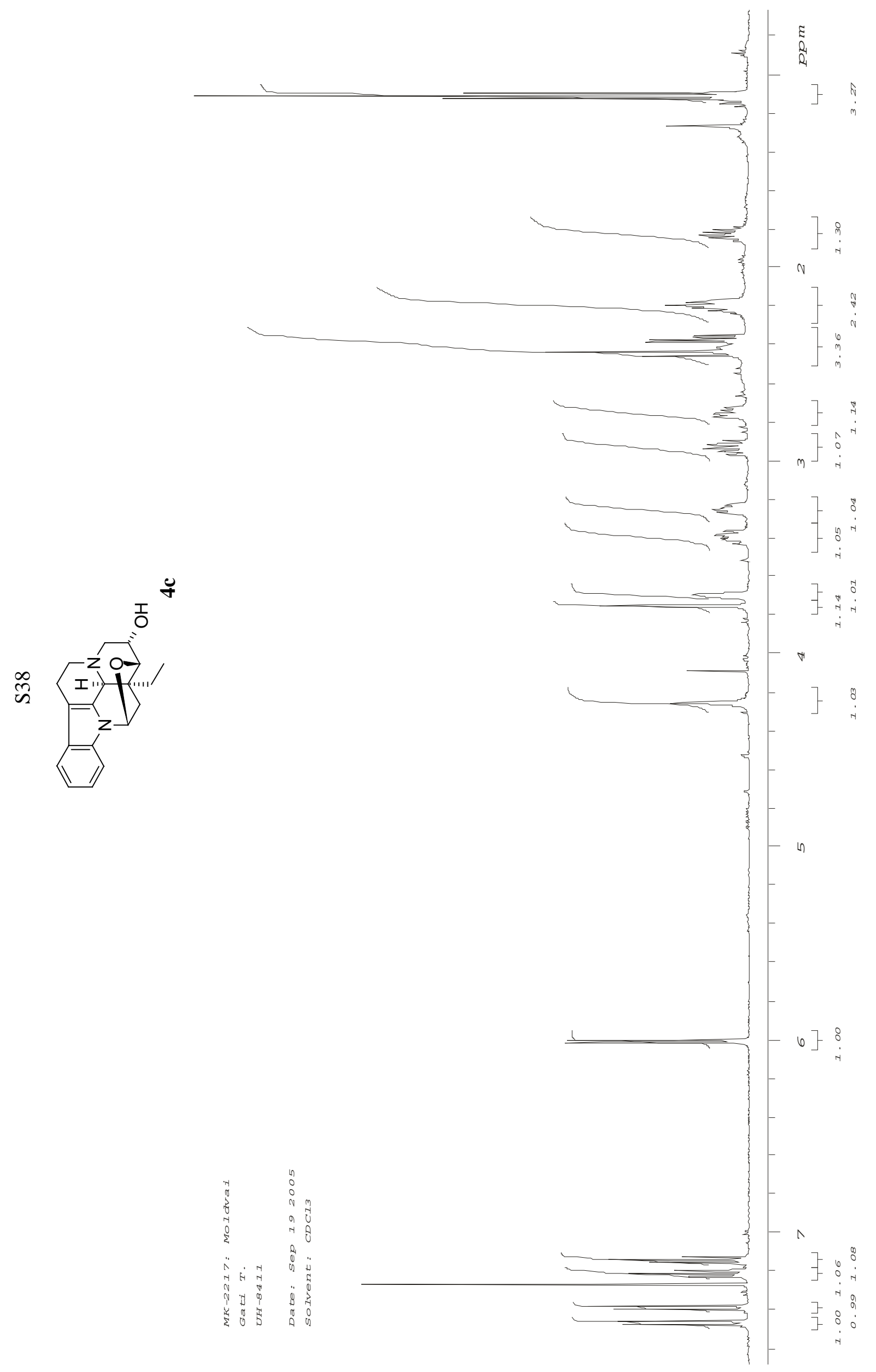




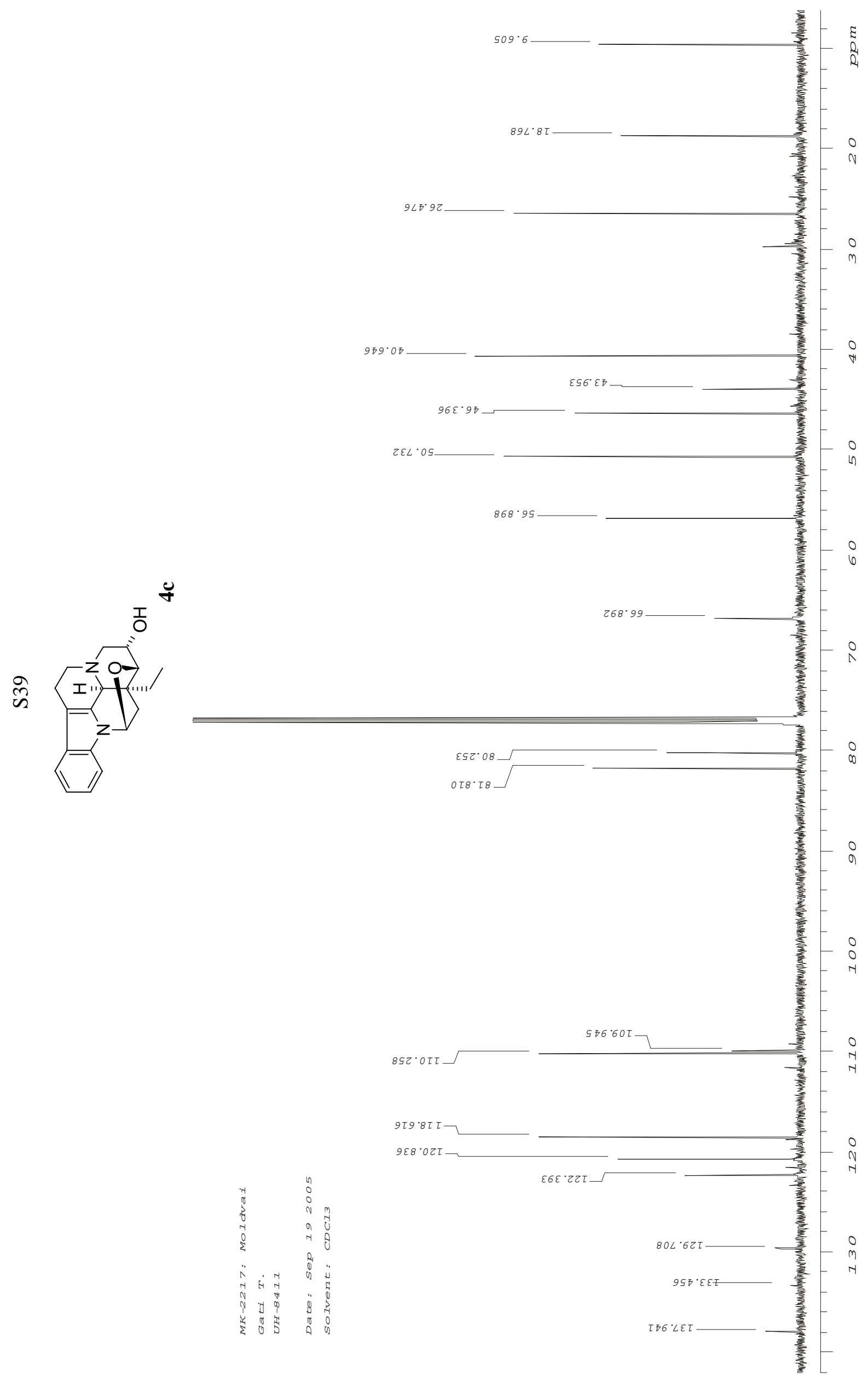




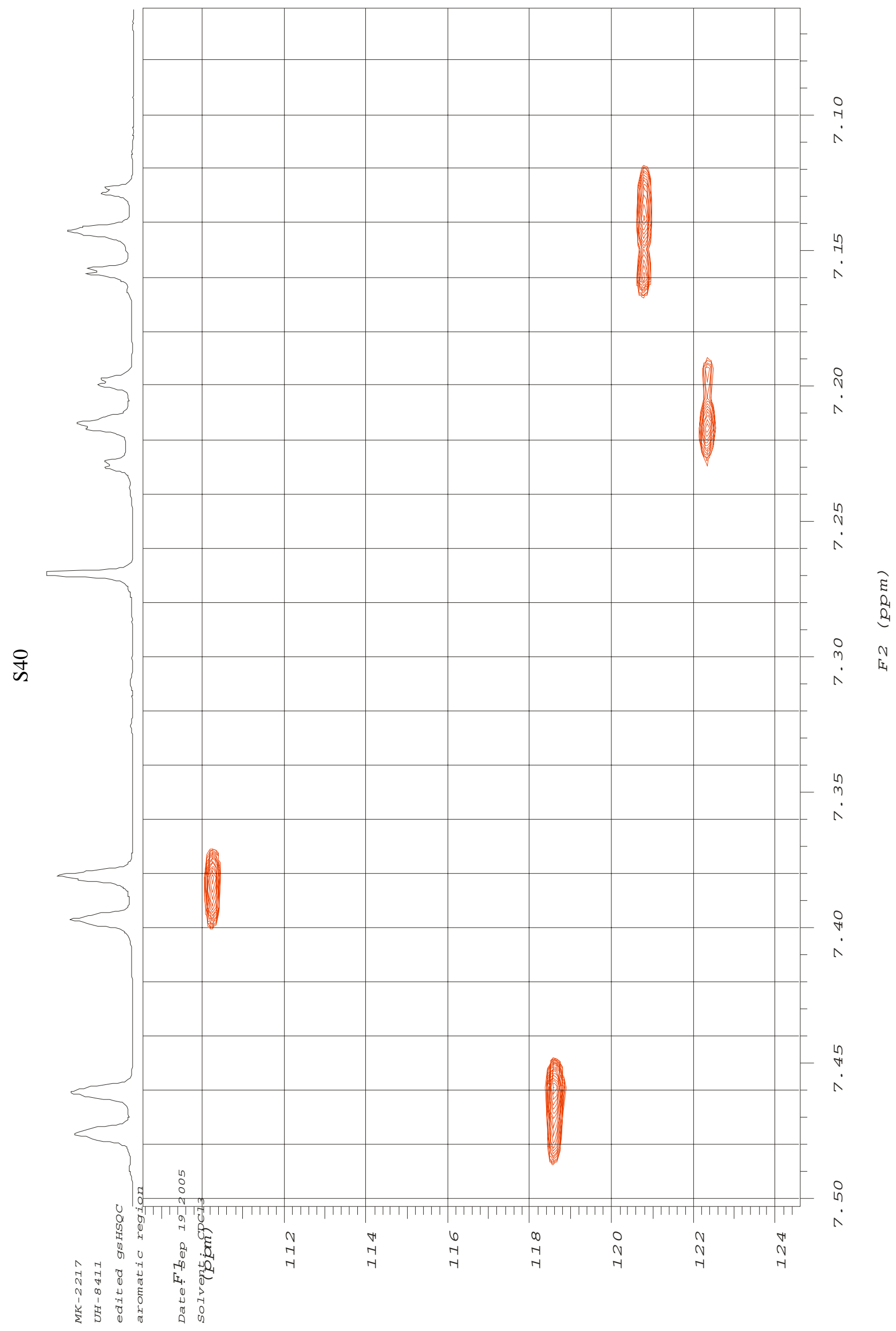




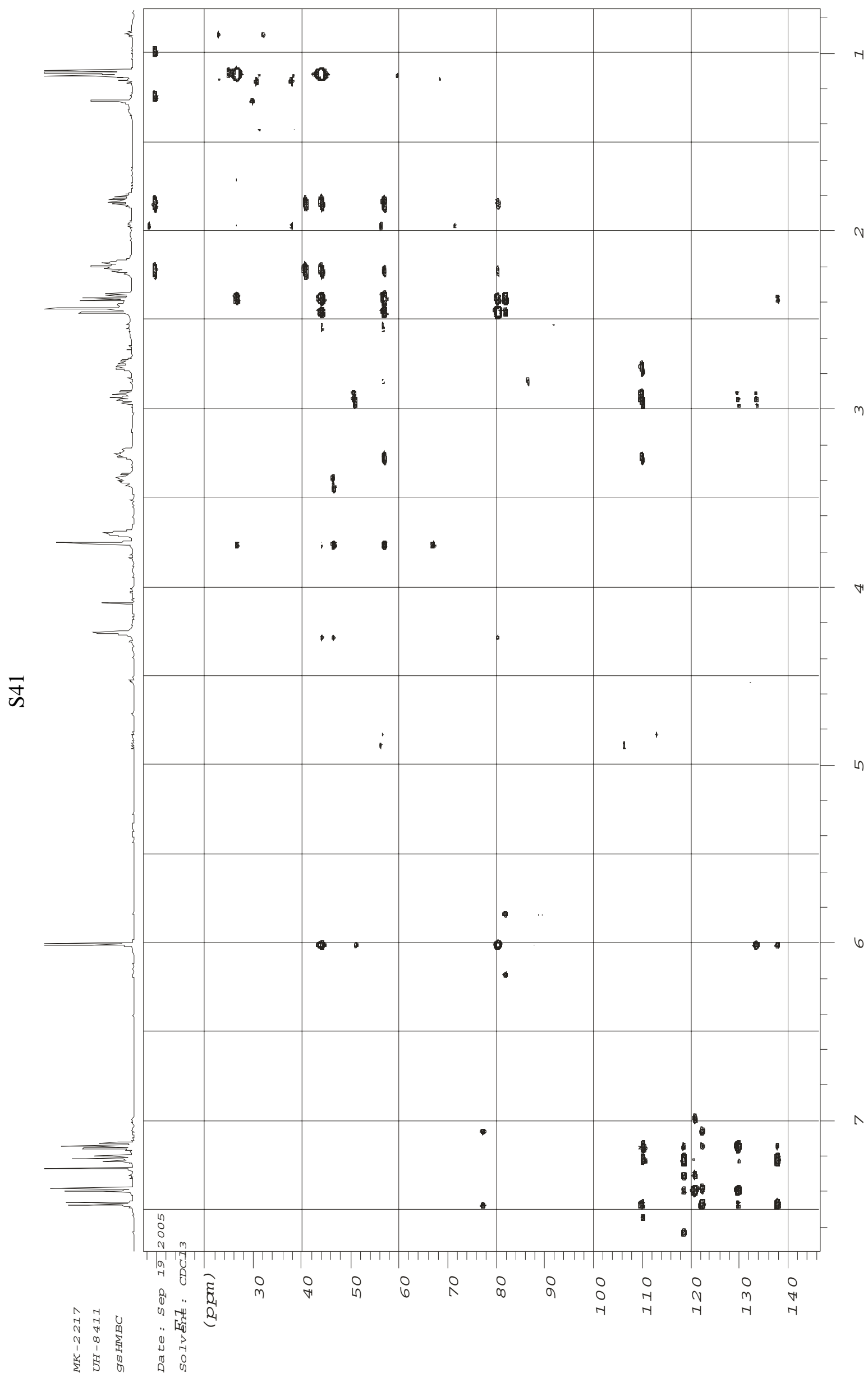




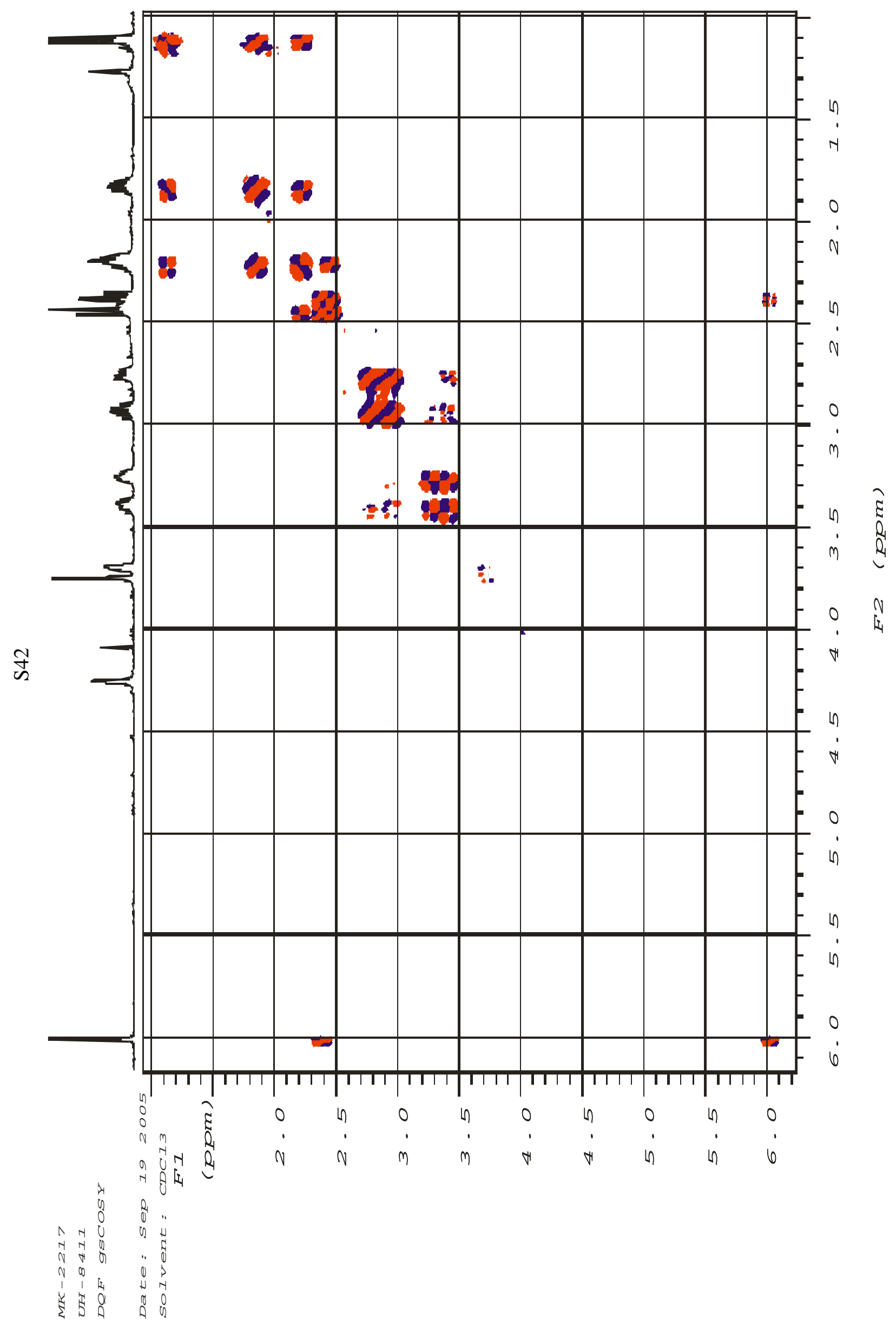

